\title{
SIQUEIROS ANTES DE SIQUEIROS
}

Por Xavier Moyssén

Se reúne en esta investigación un grupo de obras de David Alfaro Siqueiros poco conocidas, el grupo está constituido por b́leos, pasteles, acuarelas y dibujos que corresponden a los años 1911-1920; son los años formativos antes de que el artista alcanzara una expresión personal dentro del arte; no se quiere decir con esto, de manera aiguna, que a Siqueiros lè haya faltado personalidad dentro del periodo que aquí se presenta, lo que se ha querido señalar es que aún estaba ausente lo que habria de caracterizarle después: un arte con formas propias y con una finalidad social conscientemente asumida.

El título de este trabajo, ya lo habrá advertido el lector informado, no es original, se ha tomado del libro Picasso antes de Picasso, que el critico español Alejandro Cirici Pellicer dedicara nada menos que a uno de los monstruos artísticos de este siglo. Cirici Pellicer estudió las obras realizadas por Picasso entre los años 1891 a 1904. ${ }^{1}$

Desde mi punto de vista considero que también hubo un Siqueiros antes del que todo el vulgo conoce, un Siqueiros tan importante como el último, pues éste no se explicaría sin el que corresponde a la primera etapa, a la formativa, a la de búsquedas.

En torno a ese periodo del cual esta investigación es un intento de acercamiento, se ha tendido una cortina de silencio, se ha pretendido ignorar los valores que encierra, actitud asumida incluso, por parte del mismo artista, el cual tan proclive que era para hablar de sí mismo, nada dijo respecto a las obras que aquí se presentan.

Para el estudio de la vida y obra de David Alfaro Siqueiros, el crítico de arte cuenta con dos fuentes informativas indispensables. La primera está formada por las noticias biográficas que él mismo escribió a lo largo de su existencia. La segunda fuente se encuentra en las numerosas obras que con excepcional empeño ha publicado la señora Raquel Tibol. Existe, por otra parte, una importante bibliohemerografía en la que se estudia, interpreta y divulga la extensa producción del maestro; sin embargo, todo cuanto se dice de su biografia, proviene de sus propias declaraciones y escritos o de los libros de Raquel Tibol. En este trabajo queda cuestionado todo lo referente a su actuación personal compren-

1 Fi libro fue publicado por la Editorial Joaquin Gil, Barcelona, 1942. 
dida entre los años 1896-1920. Respecto a las dudas que se presentaron al desarrollar este estudio es necesario aclarar que no fue posible resolver todas. Lo que él de sí mismo dijo, resulta contradictorio en muchas ocasiones, queda la impresión de que la verdad fue tergiversada. Así, por ejemplo, hay dudas respecto al lugar de su nacimiento, parece que él fue originario de la ciudad de México y no de Santa Rosalía, hoy Ciudad Camargo, Chihuahua; la razón de esta alteración parece residir en el afán revolucionario de David Alfaro Siqueiros, de identificarse con los hombres del norte de la República, pues como se sabe muchos de ellos procedían de allá y fueron célebres caudillos en la Revolución iniciada en 1910. Cuanto aquí se asienta no fue susceptible de comprobación, proviene de las dos fuentes arriba citadas y está sujeto a una revisión posterior.

José David Alfaro Siqueiros nació en 1896. Sus padres fueron Cipriano Alfaro y Teresa Siqueiros. En 1908, cuando contaba doce años de edad, su familia se estableció en la ciudad de México. Poco es lo que se sabe stricto sensu, sobre sus tempranas inclinaciones artisticas, no obstante que existe un cuadro pintado cuando contaba once años, La Virgen de la silla, copia infantil de la famosa obra de Rafael Sanzio. Ll declaró que en el mismo año de su llegada a México su familia le procuró un profesor particular de pintura; de Eduardo Solares Gutiérrez (18881941), fue de quien recibió la primera instrucción académica.

Lo que Siqueiros dijo en diversas ocasiones sobre su ingreso en 1911 a la Escuela Nacional de Bellas Artes (antigua Academia de San Carlos), no está debidamente aclarado, resulta confuso y contradictorio. Por una parte se asienta que en ese año ingresó a la Escuela Nacional Preparatoria porque iba a estudiar Arquitectura. Por la otra que no fue admitido en la Escuela de Bellas Artes, dada su corta edad, quince años, y sí en cambio, se le admitió como alumno supernumerario en las clases nocturnas, ¿Cómo fue posible que no se le recibiera por la mañana, en razón de su edad, y sí en cambio se le aceptara por la noche? Mientras no se aclare convenientemente este punto, aceptemos lo de su ingreso en 1911 al turno nocturno y como alumno supernumerario de la Escuela Nacional de Bellas Artes. ${ }^{2}$ Por Raquel Tibol sabemos que en la vieja

2 Pese a los trámites realizados no fue posible consultar el archivo de la Escuela Nacional de Artes Plásticas para manejar la matricula de inscripciones de 1911; alli deben de constar las causas por las cuales no se le admitió en los cursos matutinos, alli también debe encontrarse la fecha exacta de su ingreso como alumno supernumerario. 
institución académica Siqueiros estudió con los siguientes maestros: "Germán Gedovius en óleo, Emiliano Valadés en desnudos al carbón, a Saturnino Herrán en figura vestida, a Francisco de la Torre en paisaje y a Carlos Lazo en historia del arte." 3

1911 fue un año difícil para la Escuela Nacional de Bellas Artes. En el mes de abril surgieron los primeros problemas originados por los métodos de enseñanza y por la arbitraria conducta del profesor encargado de la cláse de anatomía. Además, de tiempo atrás se arrastraba un conflicto ocasionado por la existencia de una sola escuela en la que se reunía tanto a los artistas (pintores, escultores y grabadores) como a los arquitectos, con el agravante de que esta última carrera era de tipo elitista, sólo podian aspirar a ella, con positivos resultados, los hijos de la burguesía porfirista; es más, el director de la escuela era un arquitecto: Antonio Rivas Mercado. Como suele acontecer en estos casos, las autoridades no prestaron atención debida a las peticiones de los futuros artistas, por lo cual el problema se agravó. El 28 de julio estalló una huelga que se prolongó hasta el año siguiente.

Contrariamente a lo que se ha venido aseverando sin fundamento real, la huelga de 1911 de la Escuela Nacional de Bellas Artes, en ningún momento tuvo móviles políticos o sociales por parte de los estudiantes y no deja de llamar la atención que no haya sido así, dado que los tiempos eran propicios para ello, pues el pais se hallaba en plena efervescencia revolucionaria. En fecha reciente he realizado con otros fines, una detenida investigación sobre la citada huelga y no encontré en los periódicos consultados, ningún planteamiento político por parte de los organizadores. ${ }^{4}$

David Alfaro Siqueiros no intervino activamente en la huelga como en distintas ocasiones él lo afirmó y se ha repetido sin más. Su nombre no aparece citado ni en las actas de asamblea de la unión de alumnos pintores y escultores de la Escuela Nacional de Bellas Artes, 5 ni en los

3 En Siqueiros. Vida y obra. Colección Metropolitana núm. 28. México, 1979, p. 21.

4 Los periódicos consultados fueron los siguientes: El Nacional, El Demócrata Mexicano, El Diario, El Imparcial, Nueva Era, La Semana Ilustrada y El Heraldo.

5 La Unión fue constituida el 24 de julio de 1910. En el libro de actas y en la fecha citada se lee lo siguiente: "En el jardín, frente a la Escuela de Comercin. a las diez de la mañana se reunieron los alumnos de la Escuela para fundar una Sociedad de Alumnos de Pintura y Escultura, José de Jesús Ibarra toma la palabra y explica el objeto. Se nombra una comisión que presida la votación y son elegidos Alejandro J. León y escrutadores Manuel T. Casas y Fidias Elizondo. La directiva quedó asf: Presidente José de Jesús Ibarra, Vicepresidente Manuel T. Casas; Secretario Boanerges Morales y Tesorero Alejandro J. León. Más cuatro vocales: Fidias 
desplegados que se publicaron en los periódicos. Una de las primeras noticias recoge los nombres de los siguientes estudiantes: Raziel Cabildo, Francisco Romano, José del Pozo, Manuel T. Casas, Miguel Ángel Fernández, José de Jesús Ibarra, Francisco de la Torre y José Clemente Orozco. En desplegados posteriores las listas de alumnos citados no incluyen en ningún caso a Siqueiros. Los principales protagonistas del conflicto fueron Raziel Cabildo, Francisco Rangel y José de Jesús Ibarra; los tres fueron aprehendidos por la policía el 28 de agosto del mismo año, por haber agredido en la puerta de la escuela al arquitecto Rivas Mercado quien iba acompañado de su esposa, los recibieron con piedras y verduras; mas no hubo, repito, ninguna razón ideológica identificada con la Revolución.

El movimiento huelgufstico detuvo los estudios académicos de Alfaro Siqueiros. Las actividades se reorganizaron bajo la dirección de Alfredo Ramos Martínez, el creador de las aún discutidas Escuelas de Pintura al Aire Libre. En la de Santa Anita le encontramos en 1913 estudiando con Ramos Martínez, de él debe haber aprendido la delicada técnica de la pintura al pastel. Años más tarde, en 1921, Siqueiros escribió lo siguiente:

Nuestras escuelas líbres son academias al aire libre (peligrosas como las academias oficiales en las que al menos conocemos a los clásicos), colectividades en las que hay maestros que hacen negocios y se impone un criterio flaco, que mata a las personalidades incipientes. ${ }^{6}$

Una actitud abiertamente revolucionaria fue la que asumieron los alumnos de la Escuela Nacional de Bellas Artes en 1914 en contra del usurpador Victoriano Huerta, si bien en esta ocasión se movieron bajo la seductora influencia del Dr. Atl. En su Autobiografía José Clemente Orozco cuenta cómo los artistas tomaron el bando de las fuerzas de la Constitución y cómo se instalaron en la ciudad de Orizaba; respecto a David Alfaro Siqueiros dice que éste en unión de Francisco

Elizondo, Adolfo González y González, Francisco Moctezuma y Fernando Romano. Para el nombre de la Sociedad, ya que existía en la Escuela La Sociedad de Alumnos de Arquitectura, se acordó denominarla: Uniơn de Alumnos Pintores y Escultores de la Escuela Nacional de Bellas Artes. A las 11.40 terminó la reunión." Debo una copia de esta interesante acta que por vez primera se publica, al maestro Francisco Díaz de León; desde aquí mi agradecimiento.

6 Lo publicó en el tercer llamamiento de "orientación actual a los pintores y escultores de la nueva generación americana". Ver Vida Americana, Barcelona, 1921, p. 3. 
Valladares fue enviado "cerca del general Diéguez que combatía al villismo en Jalisco". 7

En Acaponeta, Nayarit, Alfaro Siqueiros se incorporó a la División de Occidente que comandaba el general Manuel M. Diéguez, militar constitucionalista con acusados principios socialistas. A su lado participó en importantes campañas tanto en el centro como en el norte del país, sostenidas contra las fuerzas de Francisco Villa. Formó parte activa dentro del Estado Mayor de Diéguez, alcanzando el grado de capitán segundo. Existen varias fotografias en las que el inquieto y joven artista aparece al lado del célebre militar a cuyas órdenes permaneció, según parece, hasta 1919.

En Guadalajara, centro de la División de Occidente, Alfaro Siqueiros se encontró con la existencia de un grupo de artistas que se habjan reunido en torno a un centro bohemio, entre ellos figuraban los pintores José Guadalupe Zuno, Xavier Guerrero, Amado de la Cueva y José Luis Figueroa, entre los más sobresalientes. No tardó en identificarse con ese grupo provinciano, se integró a él, tanto en lo artístico como en lo político. Intervino en polérnicas charlas sobre las funciones sociales del arte; posteriormente tanto él como Zuno han exagerado la importancia de aquellas reuniones provincianas; Siqueiros hiperbólicamente las denominó como "Congreso de artistas-soldados".

Aunque hay que tomarlo con reservas, puesto que se trata de un testimonio redactado años más tarde, José Guadalupe Zuno escribió sobre la presencia de Alfaro Siqueiros en el Centro Bohemio, lo que transcribo a continuación:

Vino a nuestra ciudad en 1919, como teniente del Estado Mayor del señor General don Manuel $M$. Diéguez, pues él y la mayoría de su generación se agregaron a la Revolución en cuanto el señor Carranza entró a la Capital del país, inspirados para ello por el ejemplo y la palabra de Atl. Ingresó David al grupo del Centro Bohemio, ya muy acrecentado para entonces. Pintó mucho aquí, pero nos queda, apenas, un autorretrato que hizo recientemente llegado, al pastel, que donado por mí se encuentra en el Museo Regional, junto con otros dos, de pintores del Bohemio, al óleo, uno de Amado de la Cueva, que fue traído por la primera esposa de Siqueiros, Gabrielita Amador; y otro de José Luis Figueroa. Como se ve por los retratos mencionados, Alfarito era también impresionista. (?) Ya su cultura histórica y artistica era amplia por entonces, a pesar de su juventud, pero

7 Ver p. 54 de la primera edición. Ediciones Occidente, México, 1945. 
sin embargo asistía con empeño a las numerosas conferencias que organizábamos en nuestro Estudio y discutía con todos nosotros los temas de fondo, pero ninguno lo atraía como el relativo a los procedimientos, el óleo, la acuarela, el pastel, el fresco, la encáustica, que encontraba inadecuados, pasados de uso, arcaicos. Desde entonces hablaba de pintar con pistola de aire... Siqueiros discutía también mucho las cuestiones de forma y de fondo, apuntando ya desde aquellos días todos los principios de su actual forma de pensar. ${ }^{8}$

David Alfaro Siqueiros permaneció en Guadalajara hasta 1917; regresó a la ciudad de México en donde habría de desarrollar una intensa e importante actividad antes de viajar a Europa. En la capital pintó sobre todo retratos y se dio a conocer como artista gráfico, como dibujante de ilustraciones para libros y revistas, con una producción novedosa en relación con lo que habia hecho hasta entonces. Todo cuanto realizaba no pasó desapercibido para la crítica; Raziel Cabildo le dedicó un elogioso artículo en Revista de Revistas, con un llamativo título: "Un nuevo artista: Alfaro Siqueiros." 9 Dada su importancia transcribiré algunos párrafos:

David Alfaro Siqueiros fue un mozalbete que en los buenos tiempos en que Ramos Martínez dirigió la Escuela de Bellas Artes, apareció por primera vez entre los pintores de la novísima generación, distinguiéndose por sus facultades, su inquietud y sus rebeldías. Se contó entre los alumnos de paisaje de la Escuela de Santa Anita y expuso en el Pabellón Español, el año de 1914, algunos panneaux y estudios de figura con éxito... Pintor por excelencia ... lejos de él las retóricas plásticas. Es un pagano que pinta por el encanto del matiz y el placer del modelado... Colorista opulento, de técnica vigorosa y amplia, envuelve a sus figuras en armonías audaces, no exentas de extravagancia, pero que dejan ver en el espectador una amable sensación de espiritualidad y de verismo. Otra de las faces interesantes de Alfaro Siqueiros es la de ilustrador. Su composición a ratos incongruente, se preocupa más que de las ideas, de los medios plásticos que las informan ... Capítulo especial merecen los retratos que pinta Alfaro, por la originalidad de su composición y su sugestiva espiritualidad.

8 Las noticias que ofrece Zuno son interesantes, sin embargo, ya se ha advertido, hay que tomarlas con cautela, se trata de recuerdos de fijación tardia y los juicios no son atinados, por ejemplo cuando califica a Siqueiros de "impresionista". Vide Las artes pldsticas en Jalisco. Ensayo critico-histórico, Ediciones "Et Caetera", Guadalajara, Jal., 1953, p. 132.

9 Apareció el 27 de octubre de 1918, en la página 14. 
Raziel Cabildo concluye su artículo de manera casi profética:

$Y$ para terminar, vaya un voto ferviente porque este joven pintor, que tan rigurosamente se inicia en su carrera, no sea una de tantas victimas de nuestro medio y porque el éxito más completo premie sus nobles esfuerzos y la altitud de sus aspiraciones.

Antes de que finalizara 1919 y sin mayores recursos económicos que su haber de capitán ségundo del ejército mexicano, partió haciá Europa. A su paso por New York se encontró con José Clemente Orozco. E] viaje fue fundamental para su formación artística y para el sentido que habría de dar a su vida y obra en adelante. A su retorno a México aparecerá como un nuevo artista que dejará sentir su presencia en los murales de la Escuela Nacional Preparatoria y en cuadros de caballete como la Madre proletaria. Pero aquí se imponen varias preguntas: ¿Qué fue lo que Alfaro Siqueiros vio allá y más le impresionó? ¿Qué museos y galerías de arte frecuentó? ¿Ante qué maestros, tanto del pasado como de su presente se detuvo, para el aprendizaje forzoso que todos los artistas hábilmente adquieren? ¿Qué países visitó? ¿España, Francia, Italia... ? Son preguntas que sólo a medias se pueden contestar y para ello nos ayudaremos con la revista Vida Americana, de la que él fue jefe de redacción y director artístico. En los "Tres llamamientos de orientación actual a los pintores y escultores de la nueva generación americana", él cita entusiasmado a Cézanne, seguramente por influjo de Diego Rivera, quien tardiamente lo habia descubierto. En Sebastián Sunyer, en Pablo Picasso y Juan Gris, encontró "tres españoles de genio y de su época". Le interesaron tanto Georges Braque como Gino Severini, de quienes incluyó en la revista dos fragmentos de sus escritos. En más de un punto debió estar de acuerdo con las teorias del maestro uruguayo Joaquín Torres García. Pero de todos los artistas con los que se relacionó en París, recibió un fuerte impacto de Diego Rivera, ante todo era un compatriota suyo; juntos visitaron museos y galerías de arte, Rivera lo introdujo en los medios artísticos que frecuentaba y lo puso al tanto de las últimas corrientes del arte europeo, incluso el dadaísmo. Siqueiros advirtíb lo que la pintura cubista debía al arte africano y gracias a ello pudo escribir lo que sigue para aplicarlo al arte de América Latina:

La comprensión del admirable fondo humano del "arte negro" y del arte "primitivo" en general, dio clara $y$ profunda orientación a las 
artes plásticas perdidas cuatro siglos atrás en una senda opaca de desacierto; acerquémonos por nuestra parte a las obras de los antiguos pobladores de nuestros valles, los pintores y escultores indios (mayas, aztecas, incas, etcétera); nuestra proximidad climatológica con ellos nos dará la asimilación del vigor constructivo de sus obras, en las que existe un claro conocimiento elemental de la naturaleza, que nos puede servir de punto de partida.

De todo cuanto vio en París, los futuristas italianos debieron llamarle poderosamente la atención, por el ímpetu plástico existente en las formas de sus cuadros, por la novedad inquietante de sus manifiestos, por lo revolucionario que vio en ellos. Mario de Micheli ha escrito que cuando Siqueiros pasó por Milán en 1919 visitó a Carlo Carrà, noticia dudosa, pues el mexicano en ese año no abandonó París. Del tiempo vivido en Europa nunca dijo lo suficiente, no llegó a explayarse como de otros periodos de su activa existencia; lástima es, pues sería un documento de un valor inmenso para comprenderle mejor dentro de esta etapa formativa y decisiva. Pero de algo sí estamos informados: del trascendental encuentro que tuvo con Diego Rivera en Paris. El resultado es de todos conocido para insistir aquí; si anotáramos, como novedad, que el encuentro dio lugar a que Alfaro Siqueiros redactara un artículo sobre Rivera, el cual es quizá, su escrito más antiguo. Fue publicado en El Universal Ilustrado con el título llamativo de "Diego M. Rivera pintor de América", por el acuarelista David Alfaro Siqueiros. 10

En 1922 retornó a México con un cambio notorio de expresión, pero hay algo más: en adelante dejó de ser Alfaro Siqueiros para ser únicamente Siqueiros, es decir, que como en el caso de Pablo Ruiz Picasso, adoptó como apellido distintivo el de su madre: Siqueiros.

El cuadro de David Alfaro Siqueiros más antiguo que se conoce es la ya citada copia de La Virgen de la silla; a esta obra le sigue un pastel de considerable tamaño trabajado sobre cartón, mide $0.96 .5 \times 1.86$ metros. El tema del cuadro es Campesinos y no deja de llamar la atención pues resulta casi premonitorio, toda vez que vuelve a aparecer con frecuencia en su obra posterior aunque con otra intención (figura 1). Indepen-

10 Se encuentra inserto en el número 218, de fecha 7 de julio de 1921, pp. 20-21. 
dientemente de lo temprano de su fecha (1911) el cuadro tiene como mérito mayor lo uniforme del colorido que ambienta la escena en donde aparecen los campesinos, hombre y mujer; éstos se encuentran dispuestos en un área que comprende casi la mitad de la composición, la otra mitad es la parte más débil, es confusamente vaga en lo que allí se quiso representar. Para ser obra temprana el dibujo de las figuras es aceptable. El cuadro está firmado en el ángulo superior derecho por Alfaro.

Buena parte de las obras que aquí se presentan corresponden a retratos. Siqueiros fue todo un maestro en este género pictórico, por la originalidad de sus composiciones, por la fuerza expresiva que supo dar a sus modelos, e incluso por los efectos de volumen que alcanzó gracias al empleo de materiales modernos como la piroxilina. Él fue uno de los grandes retratistas del arte mexicano de este siglo.

El retrato de Cipriano Alfaro, padre del artista, está fechado en 1912, mide $0.74 \times 0.65$ centímetros (figura 2). Es probable que el cuadro lo haya pintado en la fecha indicada, sin embargo, la firma que ostenta no corresponde a esa época, está sobrepuesta a la tela posteriormente; sólo aparece el apellido Siqueiros con la grafía que es común en su obra mural y de caballete. El retrato es de una factura mediocre tanto en el dibujo como en el color; fuera del tono encendido del rostro y del blanco del fondo, lo que se impone es una coloración azul verdoso. Sin embargo, aquí aparecen dos detalles que serán una constante en los retratos que llevan una fecha posterior: la figura aparece cargada completamente hacia el lado derecho y las manos se distinguirán por la elegante delgadez de los dedos; lo cual me hace suponer que el retrato fue pintado entre 1917 y 1918 , pues por su estilo recuerda los de Carlos Orozco Romero y José Luis Figueroa, que corresponden a esos años.

José Guadalupe Zuno afirma que el Autorretrato de Siqueiros que se conserva en el Museo Regional de Guadalajara, lo "hizo recientemente llegado" a la capital tapatía, es decir que de ser veraz la noticia se puede fechar entre 1914 o 1915. Se trata de una obra no carente de interés. El autorretrato, trabajado hábilmente con el lápiz carboncillo, nos entrega la imagen romántica de un joven artista de grandes y separados ojos, los cuales están dirigidos con un cierto aire de melancolía hacia el presunto espectador; hay en el diseño de la boca, un sensualismo contenido engañosamente. El trazo del lápiz en el dibujo del pelo es ágil, está realizado a base de grandes y desenvueltas curvas; de factura aceptable es también la modelación del rostro (figura 3).

Un Autorretrato más, pintado al pastel en 1916, se exhibe en el citado 
museo de Guadalajara (figura 20). No está de más recordar aquí que Siqueiros estudió en 1913 con Alfredo Ramos Martínez, en la Escuela al aire libre de Santa Anita. Ramos Martínez ha sido el maestro más conspicuo de la pintura al pastel, dentro de la pintura mexicana; a su lado Siqueiros aprovechó, sin lugar a dudas, las enseñanzas del maestro. Tal cosa se desprende, al menos, ante este interesante autorretrato, el cual está trabajado con la seguridad que da la posesión de una técnica bien asimilada. El cuadro nos muestra en medio de ágiles trazos, al joven artista de veinte años de edad, elegantemente vestido. La expresión sicológica que guarda es de inspiración romántica; los grandes y melancólicos ajos trasmiten las profundas vivencias interiores de un espíritu inquieto; el tupido bigote separó, con cierta torpeza, la distancia normal entre la nariz y los carnosos labios. Este autorretrato, pese a lo que se pueda indicar en su factura, es una obra singular en la temprana producción de Alfaro Siqueiros.

El retrato de Cipriano Alfaro fue pintado en México, en la casa que la familia habitaba en la colonia San Rafael, alli mismo hizo los de Carlos Orozco Romero y de José Luis Figueroa, entre otros. Hay en los retratos de esta época una tendencia a retener ciertos estados anímicos, como la melancolía o la tristeza declarada; quizá ello haya obedecido a la edad del pintor y la de sus modelos. Esos estados de ánimo están reflejados profundamente en los rostros, en lo alargado de las manos y la coloración que guardan dentro de la composición. En estos retratos Siqueiros se muestra como un pintor expresionista de singular fuerza, por desgracia $\sin$ repercusiones posteriores (figuras 4 y 5 ).

Siqueiros regresó a México hacia 1917 a continuar sus estudios artísticos, aunque continuaba dependiendo del centro militar de Guadalajara. En la Escuela Nacional de Bellas Artes alcanzó a Saturnino Herrán en el último año de su vida, de él recibió una influencia que aparece en las obras de esa época. Páginas atrás se ha anotado ya que en la capital se dio a conocer como ilustrador de libros y revistas. La niña de los girasoles es un dibujo a tinta china que hizo para ilustrar la portada de un número de Revista de Revistas. ${ }^{11}$ El trazo fuerte que hay en la línea de este dibujo contrasta notablemente con la delicadeza de expresión que encontramos en otras obras. En esta etapa no hay un estilo definido en el artista, se trata más bien de un etapa de búsqueda y de problemática insatisfacción. La persistencia de un gusto morboso por la languidez de las manos, está presente en este dibujo (figura 6).

11 Apareció en el número 443, del 27 de octubre de 1918. 
La búsqueda hacia una expresión propia obliga a Siqueiros al estudio de diversas técnicas; entre éstas pronto llegó a dominar la acuarela, la cual combina con el dibujo a tinta o lápiz, he aquí una de las enseñanzas debidas a Herrán. En El señor del veneno (figura 7), aplica sabiamente el trazo del crayón con los colores de la acuarela, no hay titubeos en la realización. Aquí la influencia de Saturnino Herrán queda manifestada en la leve y ritmica curvatura de las piernas de los hombres, hay en su diseño un eco que se desprende de Guerreros indigenas, dibujo acuarelado que Herrán hizo como proyecto para la decoración mural Nuestros dioses, y que Siqueiros debió conocer.

El Universal Ilustrado de fecha noviembre 15 de 1918, publicó una curiosa nota que acompaña dos dibujos de Siqueiros. La nota se titula "Los dibujos de Daniel Alfaro Siqueiroz". Tal vez por un error aparece como nombre del artista el de Daniel y no el de David, pero en donde si no existió error alguno es en el segundo apellido, aparece éste escrito con una $z$ al final, pues para el anónimo autor de la nota, la familia materna del pintor era de origen lusitano, lo cual le permtió escribir lo siguiente: "En su ascendencia portuguesa se podría encontrar el vigor de técnica que ilustra sus dibujos"; juicio bastante dudoso, pues cierto o no lo del origen portugués, ése no es criterio para calificar un gusto artístico. La breve nota se cierra con las siguientes palabras, ahora sí, llenas de verdad: "Alfaro Siqueiroz muy joven aún, definirá rápidamente su personalidad. Hay en él la madera de un pintor y un dibujante diestro y fuerte". Por su parte Raziel Cabildo también indicó la ascendencia lusitana de Siqueiros en su artículo citado en la nota 9.

El triunfo de la Gracia sobre la Fuerza, tal es el título del primer dibujo (figura 8) se trata de una alegoria hecha a propósito del fin de la Primera Guerra Mundial. En medio de un campo desolado en donde aún se perfila siniestramente un cañon, aparece la figura de la Gracia representada por una esbelta y joven mujer, quien lleva en la diestra, la cabeza recién decapitada de un gigantón que simboliza a la Fuerza bruta que toda guerra desata; su enorme cuerpo está de pie, atado a un árbol Hay una idea de origen romántico en esta ilustración: la fuerza de la guerra sólo se detiene cundo interviene la gracia femenina, un romanticismo expresado a la manera de los simbolistas. Sin embargo, el origen de la alegoría viene de lejos, encuentra sus antecedentes en temas como el de Judith y Holofermes, en el de Dalila y Sanzón y en el de Salomé y el Bautista. Cuando hay que terminar con el poder de una enorme fuerza, espiritual o material, el vehículo parace ser siempre la mujer. 
Pero hay algo más en este dibujo, en él por vez primera, Siquieiros acusa un gusto hacia las figuras decapitadas, al año siguiente en otra ilustración referida también al fin de la guerra, reaparece el decapitado, en este caso se trata de Jesucristo, ver figura 17.

El segundo dibujo Las calaveras de azúcar, tiene su origen en las celebraciones populares de las "fiestas de muertos" (figura 9) . El curvilíneo cuerpo de una adolecente que lleva con desenfado la cuerda de sus saltos aún infantiles, se destaca contrastante ante la figura compuesta a base de ejes diagonales, de una mujer indigena que vende las calaveras de azúcar que con gusto indiferente a lo que representan, habrán de engullir los compradores. La ilustración lleva en sí un sencillo simbolismo, el de la existencia y su ocaso, pero visto el final con un sentido festivo, a la mexicana con los dulces; si bien Siqueiros nuevamente recurrió a la figura de la mujer como símbolo. La existencia vista en una de sus fases iniciales está representada por la mujer cuasi niña, la fase intermedia la cubre la mujer indígena y el fin de la existencia está presente en los cráneos, supongo que femeninos, de las "calaveras de azúcar".

En estos dibujos en los que la huella del art-nouveau está presente, David Alfaro Siqueiros se muestra como el último artista afiliado a la corriente simbolista, ¿es así? En todo caso la respuesta la habrá de ofrecer en fecha próxima el profesor Fausto Ramírez Rojas, en una investigación que prepara sobre el simbolismo en el arte de México.

Para ilustrar la narración de el Abate de Mendoza, "La señorita inconsciente" y el poema Bacanal, de Alfonso Camin, David Alfaro Siqueiros hizo dos dibujos que se publicaron en la revista Album Salon que editaba Enrique Vicente Sesto. ${ }^{12}$ De todo lo que al artista hizo en 1919 estos dibujos poco le favorecen, son obras de compromiso, para salir del paso, son de encargo y por lo tanto circunstanciales (figuras 10 y 11). Sin embargo, en Bacanal manejó con fruición delectiva, un ondulante cuerpo femenino que entre nebulosas alcohólicas se aparece al bebedor. Si me he detenido en señalar este detalle, ello obedece a que en Siqueiros existió un pintor cargado de un sensualismo erótico del cual nada han querido decir sus críticos.

Como un artista versátil se nos presenta Siqueiros en las ilustraciones que hace en 1919. Así una nueva manera es la que muestra en los doce dibujos a tinta que hizo para el libro de poemas Con la sed en los labios,

12 Vide t. 1, núm. 9, sin número de página, México, mayo de 1919. Es posible que también sea obra suya la ilustración de "La leyenda del crisantemo", de Miguel A. López que alli mismo se publica. 
de Enrique Fernández Ledezma. ${ }^{13}$ Hay en esos dibujos una cierta influencia del art-nouveau que para esos años expiraba en México en cuanto a estilo, pero más que hablar de art-nouveau quizá sea más propio decir modernismo, que fue así como en el país se presentó en las ilustraciones de Saturnino Herrán, Carlos Neve y Roberto Montenegro. El dibujo inicial del libro es un retrato idealizado del propio poeta, de Enrique Fernández Ledezma; como retrato hay que incluirlo entre los de esa época. Las otras láminas acusan una mayor o menor fantasia, adecuada en todo caso al tema del poema (figuras 12 y 13).

Por Raziel Cabildo nos informamos que Siqueiros compuso hacia 1918, "una serie de acuarelas... sobre motivos de danzas...", sin embargo, nada nos dice del número que formaba la serie. En la revista El Universal Ilustrado se publicaron como portadas, dos de estas acuarelas: La danza de la lluvia y Bailarina oriental. ${ }^{14}$ De no estar firmados estos dibujos iluminados, bien podría uno negarse a reconocerles tal paternidad; son de lo más insólito dentro de su producción, sobre todo el que se ocupa de La danza de la lluvia (figura 14). Aquí alcanzó el artista un refinamiento en la expresión lineal que no volverá a repetirse en su obra posterior. El elegante cuerpo de la danzante pone de manifiesto su elasticidad en esa línea continua que modela su silueta. Guardando un mesurado equilibrio con la delicadeza de la figura, están aplicados los tenues colores acuarelados que Siqueiros manejó diestramente.

A propósito de esta serie, Cabildo escribió que:

...las bailarinas de Alfaro son un torbellino de miembros, de paños enloquecidos, de carnes jadeantes que cruzan una atmósfera matizada por todas las indecencias, descoyuntados, de escorzos indecibles. Y eso es lo justo, eso es lo verdadero. Tal es la sensación que queda en el recuerdo después de una fiesta de la danza. ${ }^{15}$

El flexionado cuerpo de la Bailarina oriental, responde sólo en parte a las observaciones de Raziel Cabildo. No obstante la gracia que posee la figura, la sensación de movimiento está ausente en ella, pese al vuelo

13 Fue editado por México Moderno, en el citado año; aparte de los dibujos de Siqueiros el libro incluye otros debidos a la pluma de Gabriel Fernández Ledezma. Tres de los dibujos de Siqueiros se reprodujeron en Mundo Salón, en el número 12, correspondiente a octubre de 1919.

14 La primera apareció el 24 de enero de 1919 con la siguiente leyenda: "Fantasia inspirada por la admirable euritmia de Anna Pavlova al artista Alfaro Siqueiros." La segunda fue publicada dos semanas más tarde, el 7 de febrero, con un brevísimo comentario: "Fantasia del dibujante Alfaro Siqueiros."

16 Vide nota 9. 
que tiene la falda. Aparece estática, suspendida en el espacio, su cuerpo no pesa. No sé hasta qué punto el colorido original esté alterado en la copia que manejé, de todas formas resulta más rico que en la obra anterior (figura 15). Ante estas dos láminas hay que pensar únicamente en el art-nouveau. La línea ondulada por ese ritmo ininterrumpido parece obedecer a los dictados de ese estilo, que aquí se ha interpretado de una manera muy libre, mas en realidad se trata únicamente de un eco o de una consecuencia tardía del art-nouveau, interpretado de una manera sui-generis. Para estas dos ilustraciones Siqueiros se inspiró en la gran bailarina rusa Anna Pavlova, de visita ese año en la ciudad de México. Una fotografía de un periódico capitalino muestra a la Pavlova vistiendo el traje de la bailarina oriental.

Un mes más tarde El Universal Ilustrado volvió a engalanar su portada con otro dibujo a la acuarela debido a Siqueiros, ${ }^{16}$ con el título de Los primeros frutos. Por su estilo este dibujo se relaciona con los dos anteriores. En él aparece una hermosa mujer de alargadísimo cuerpo, ante un hombre situado en la parte inferior, el cual le ofrece las primicias frutales que lleva en la batea laqueada. Sorprende la composición de esta obra tanto por la figura femenina y su colocación como asimismo por la recortada imagen de quien le entrega los frutos, únicamente se ve, aparte la mano, el perfil de su cabeza, con rasgos indigenas tan acusados como los encontramos en los dibujos de carbón de Nuestros dioses de Saturnino Herrán (figura 16).

El 3 de enero de 1919 El Universal Ilustrado incluyó en sus páginas dos dibujos alegóricos que se reproducen aquí en la figura 17. El primero corresponde al año 1918 en que terminó la Primera Guerra Mundial. Es una ilustración expresionista en la que se ve al kaiser envuelto en la penumbra, presa del pánico y sobre los cráneos de las víctimas de la guerra, está aterrado bajo el peso doble de la derrota y el juicio inminente de la historia. De los dos dibujos el segundo. está firmado por Alfaro; no obstante que en la revista se dice que los dos se deben a él, guardo grandes reservas para aceptar que el primero lo sea, su estilo es diametralmente opuesto al del año 1919.

La alegoría de 1919 es más libre, más espontánea en su realización; está relacionada con la herencia que el nuevo año recibe. De acuerdo con la iconografía tradicional el año nuevo está representado en la figura de un niño que porta el gorro frigio; va sentado sobre un extraño vehículo que es tirado lentamente por un estilizado caracol. La ilustra-

16 Apareció el 7 de marzo de 1919. 
DOI: http://dx.doi.org/10.22201/iie.18703062e.1976.45.1030

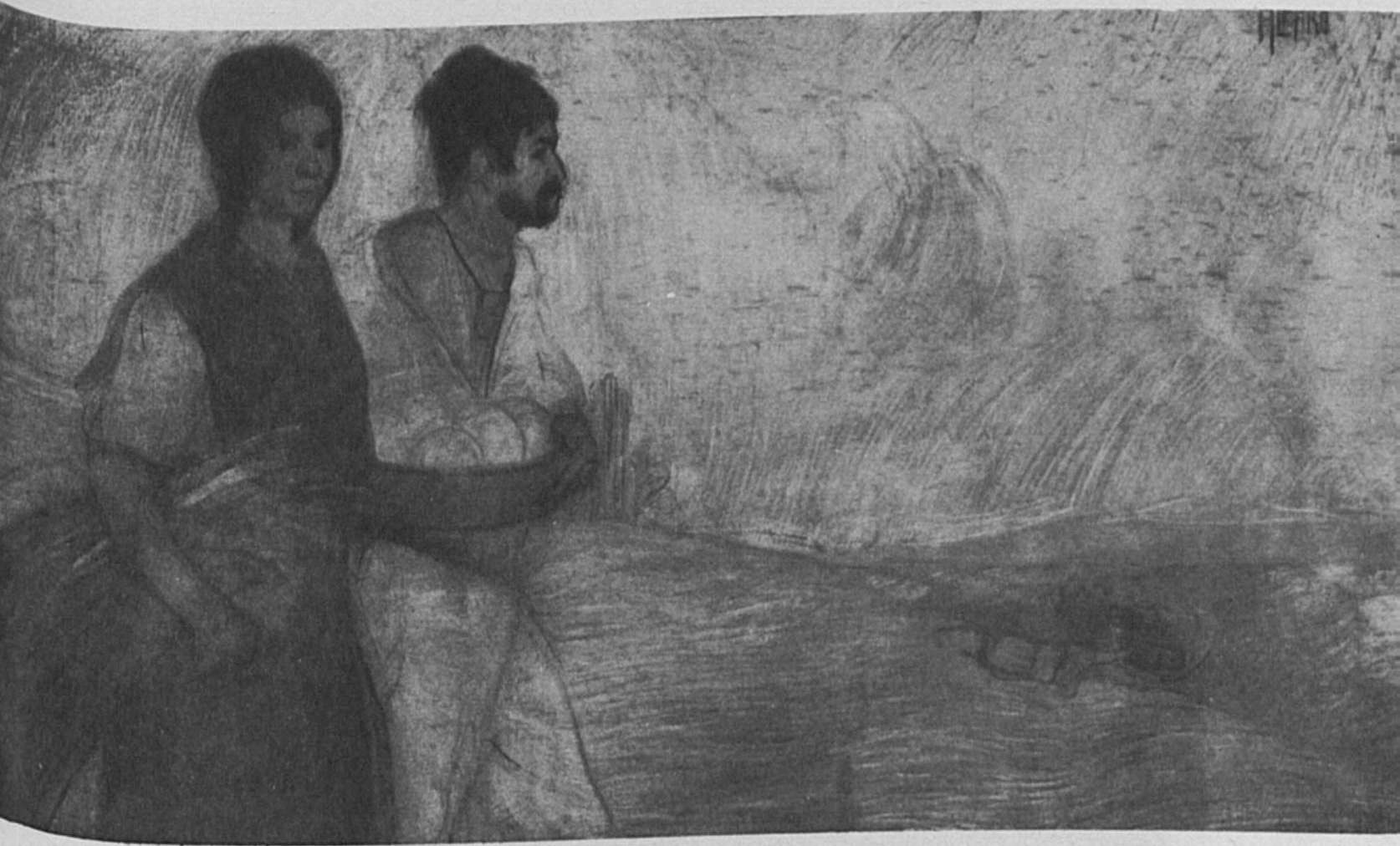

1. Campesinos. Pastel sobre cartoncillo, 1911. Colección señora Inés Amor. 
DOI: http://dx.doi.org/10.22201/iie.18703062e.1976.45.1030

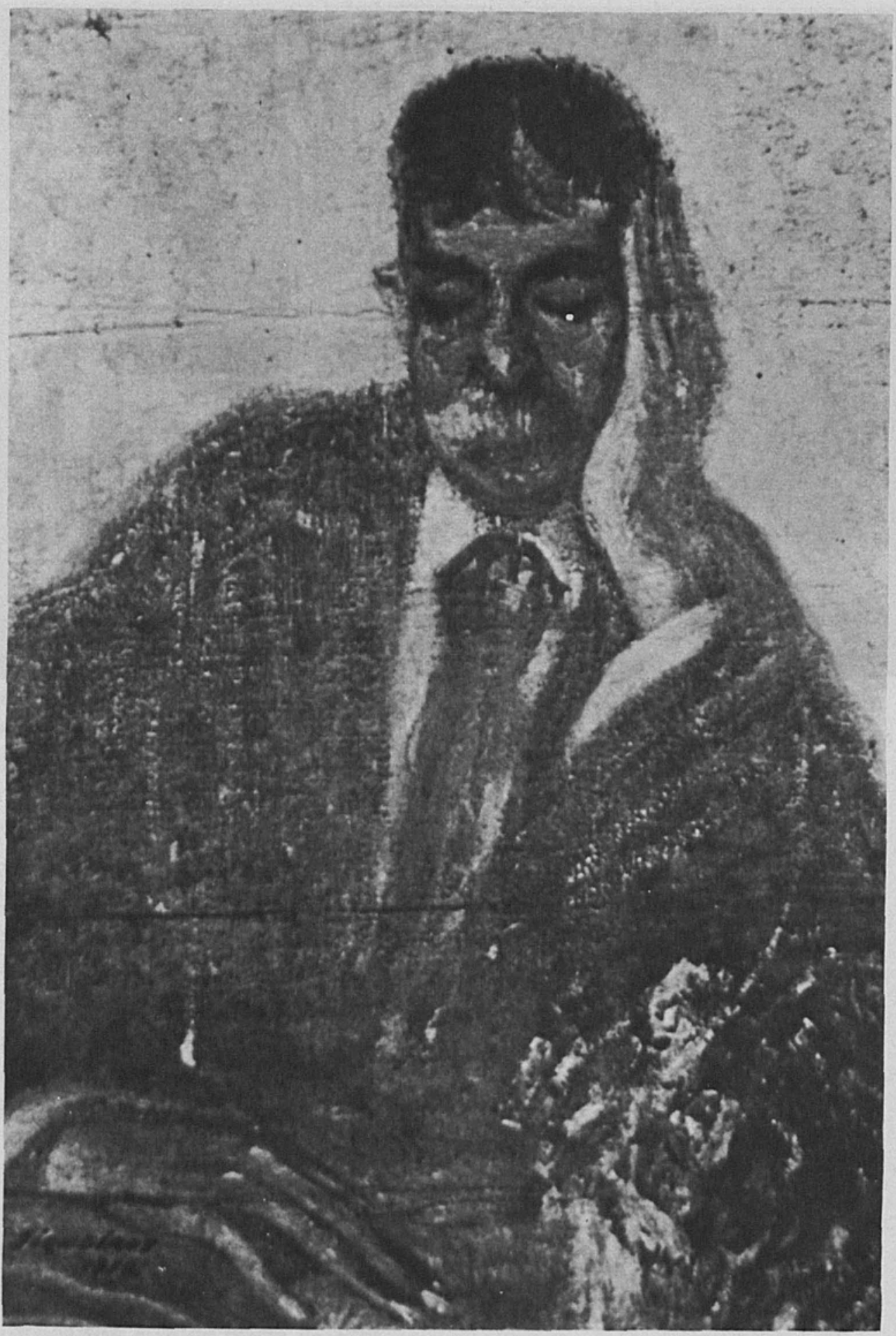

2. Cipriano Alfaro. Oleo sobre tela, 1912. Colección doctor J. Alvarez Amézquita. 
DOI: http://dx.doi.org/10.22201/iie.18703062e.1976.45.1030

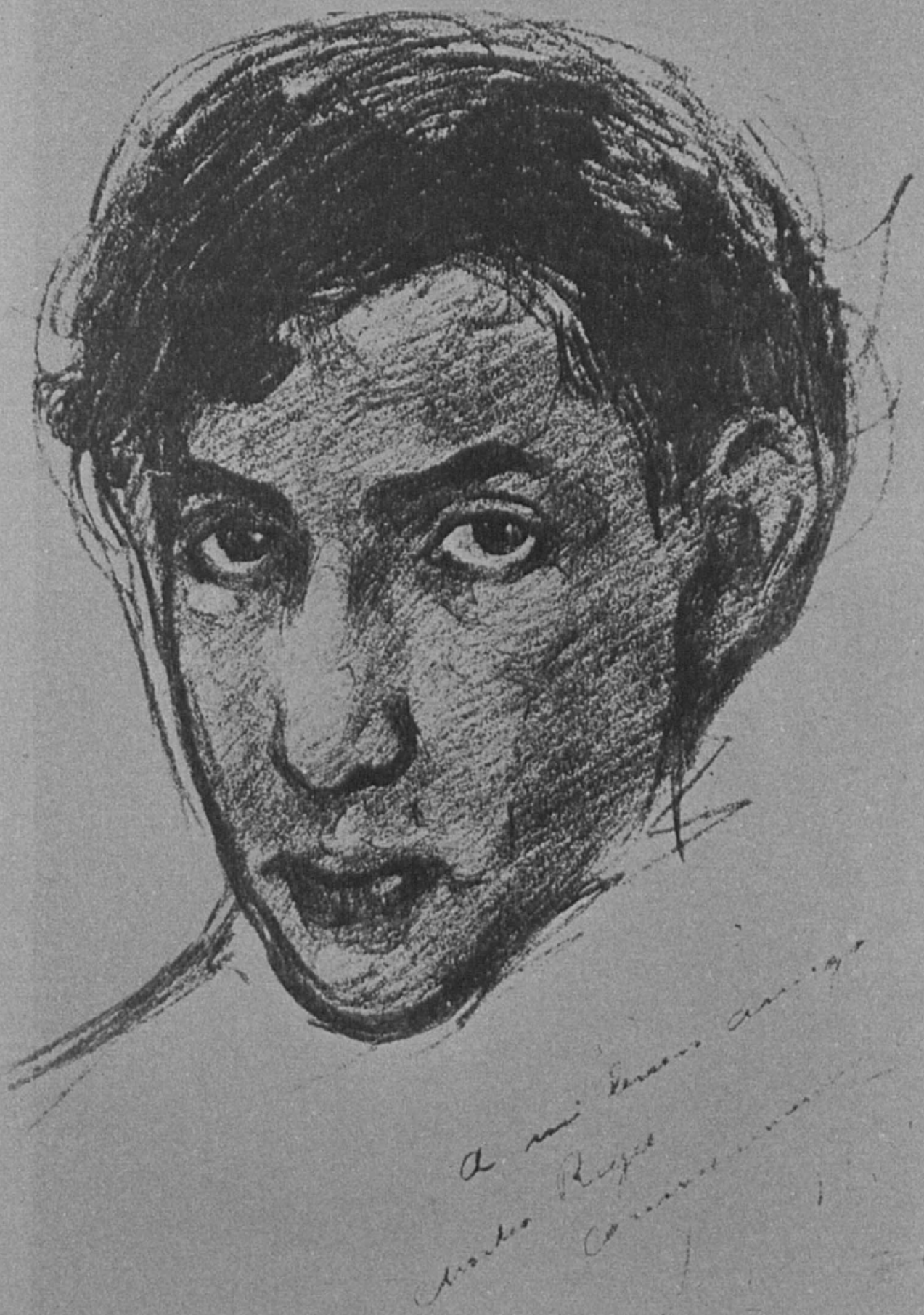




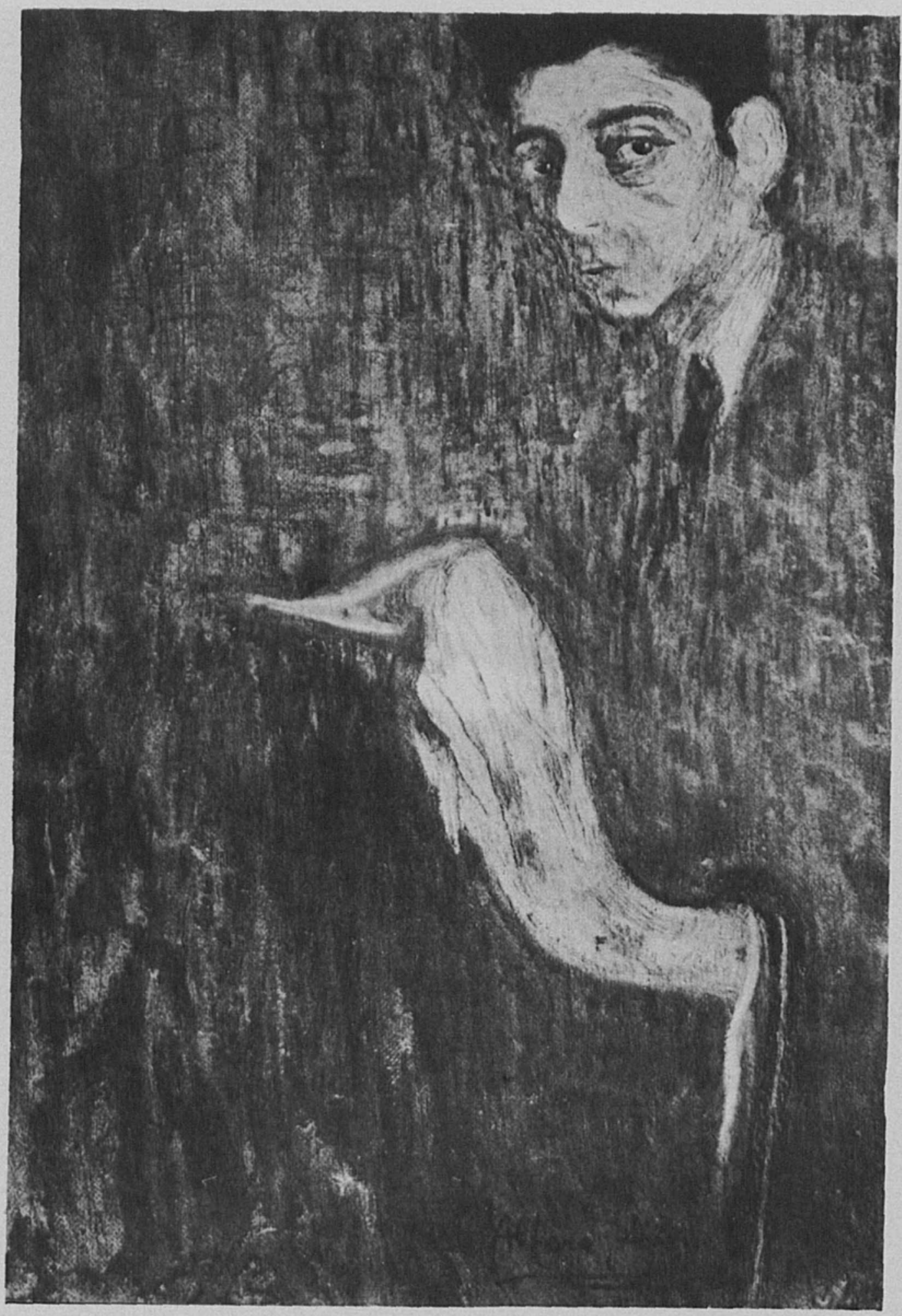

4. Carlos Orozco Romero. Oleo sobre tela, 1918. Guadalajara, Jal. Museo Regional. 
DOI: http://dx.doi.org/10.22201/iie.18703062e.1976.45.1030

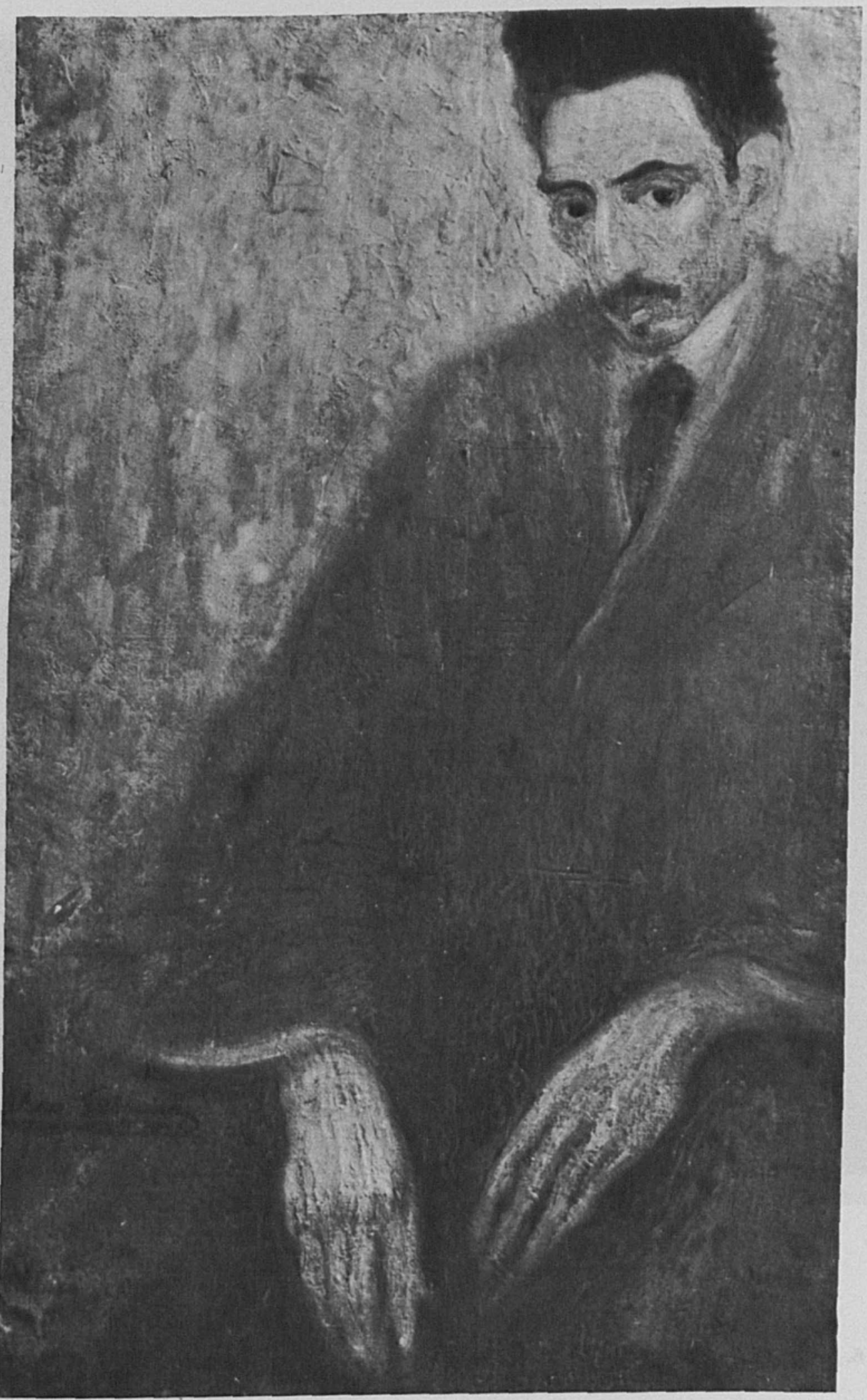

5. José Luis Figueroa. Oleo sobre tela, 1918. Guadajara, Jal. Museo Regional. 
DOI: http://dx.doi.org/10.22201/iie.18703062e.1976.45.1030

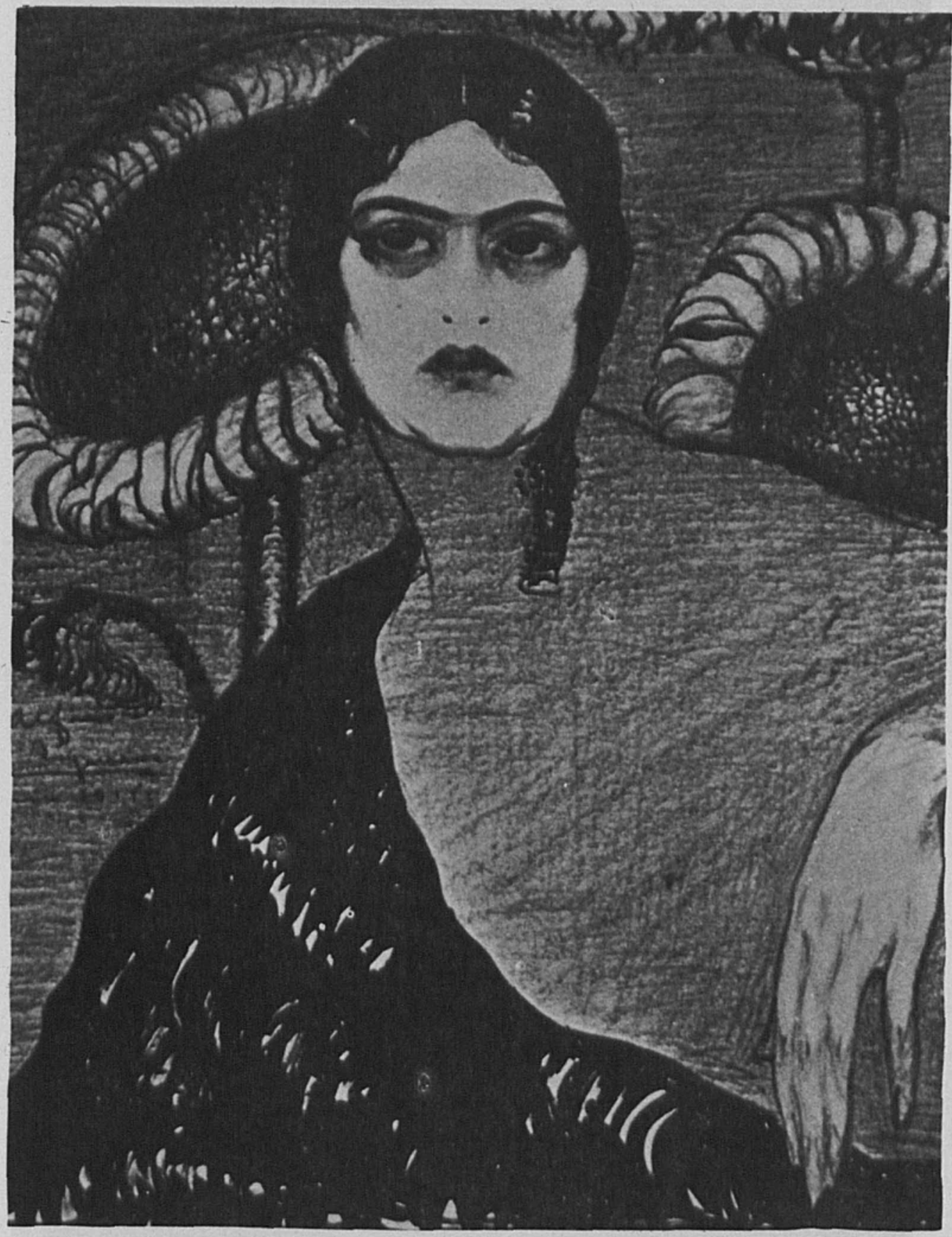

6. La niña de los girasoles. Dibujo. Tinta, 1918. Colección señora Olga Hertschel. 
DOI: http://dx.doi.org/10.22201/iie.18703062e.1976.45.1030

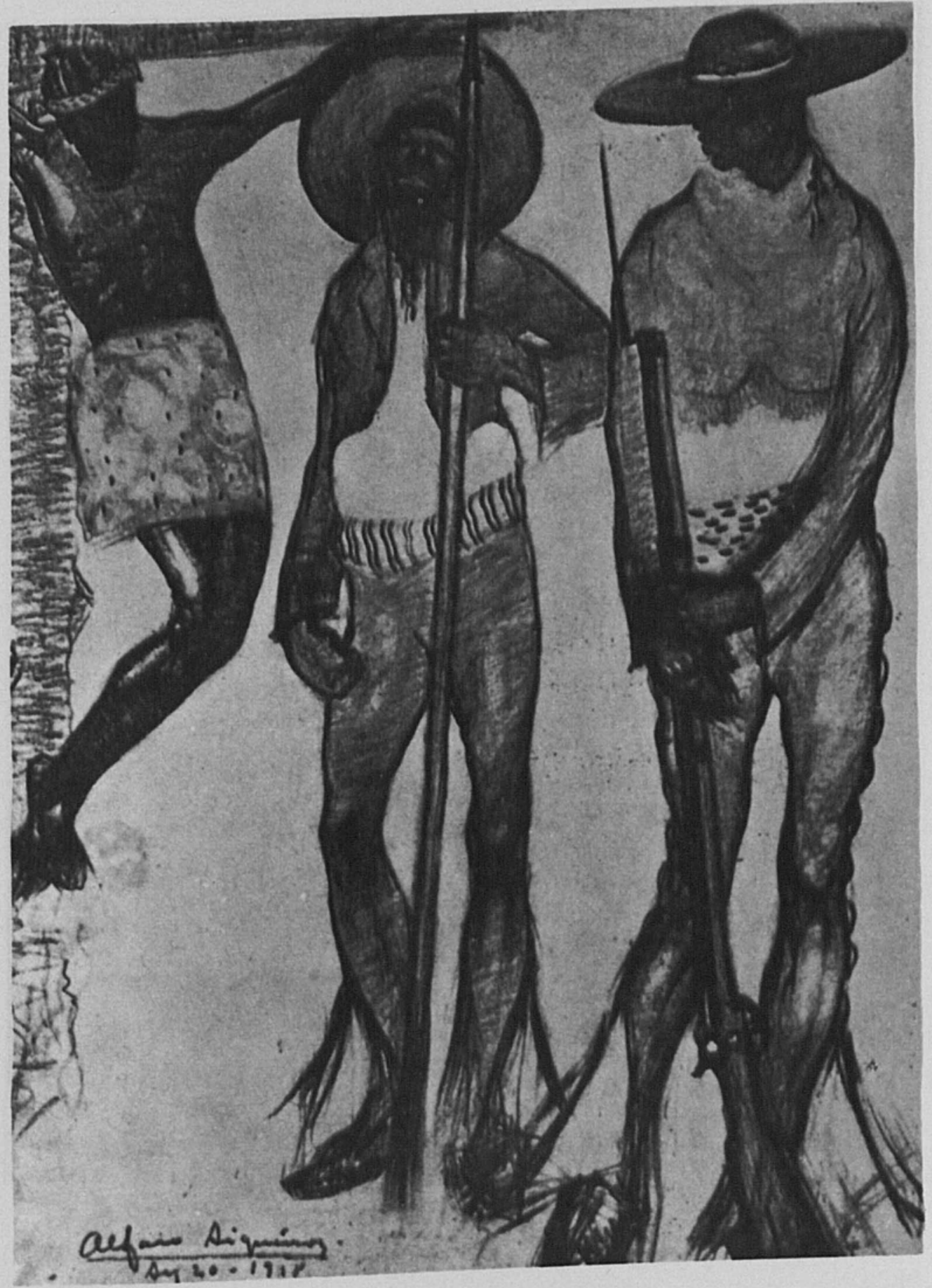

7. El Señor del Veneno. Dibujo. Acuarela y crayón, 1918. Colección señora Sofía Bassi. 
DOI: http://dx.doi.org/10.22201/iie.18703062e.1976.45.1030

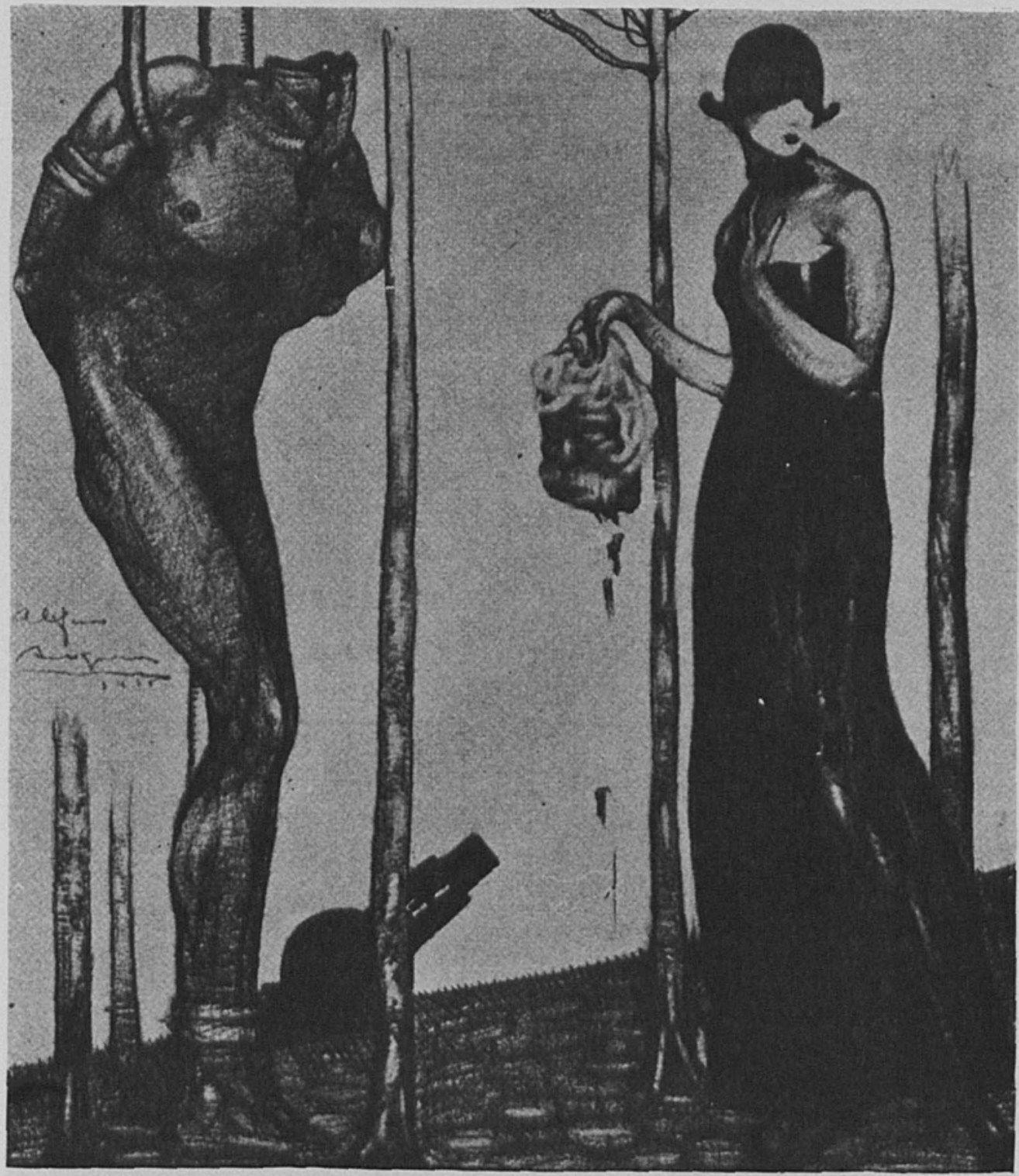

8. El triunfo de la Gracia sobre la Fuerza. Dibujo, 1918. 
DOI: http://dx.doi.org/10.22201/iie.18703062e.1976.45.1030

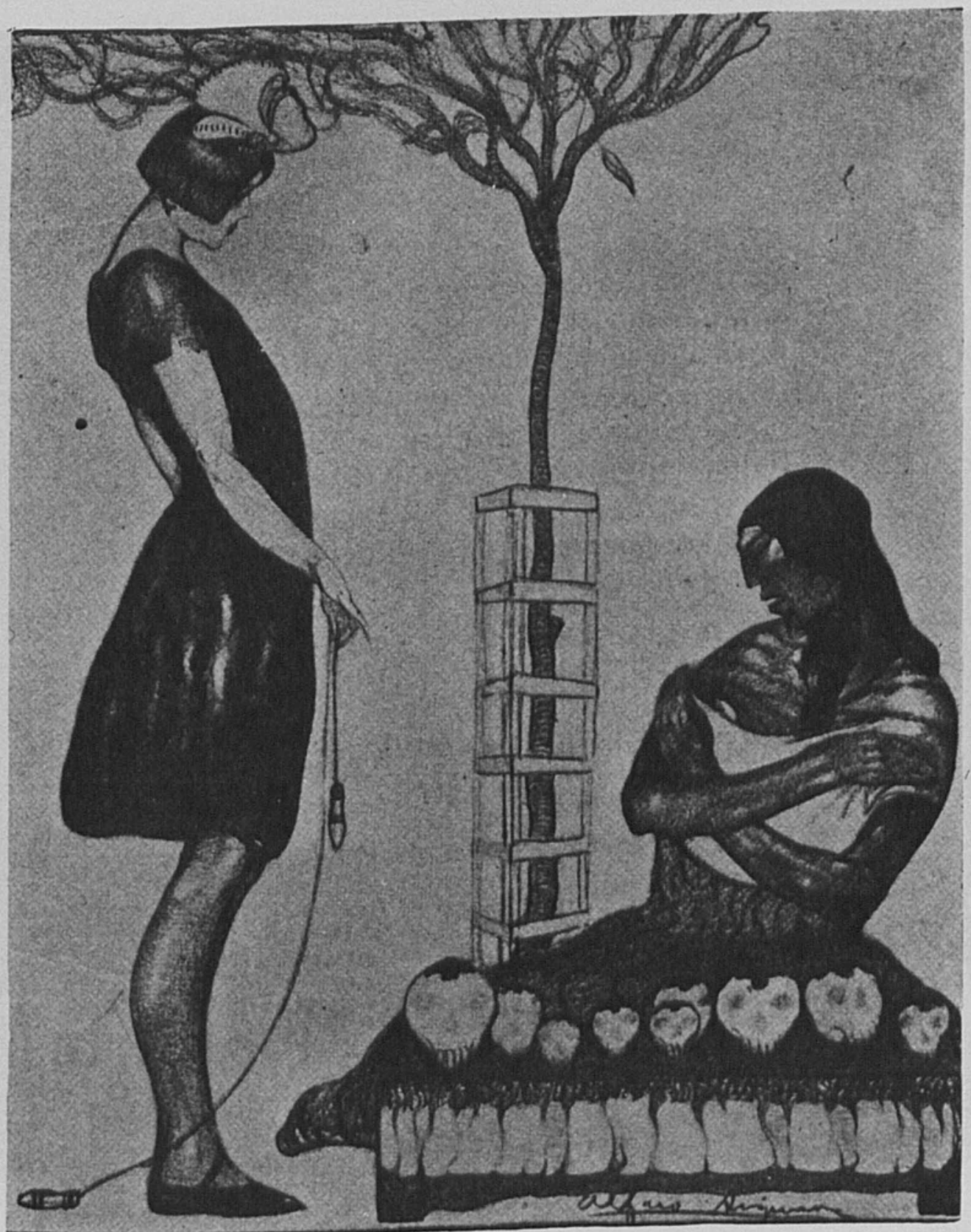

9. Las calaveras de azúcar. Dibujo, 1918. 
DOI: http://dx.doi.org/10.22201/iie.18703062e.1976.45.1030

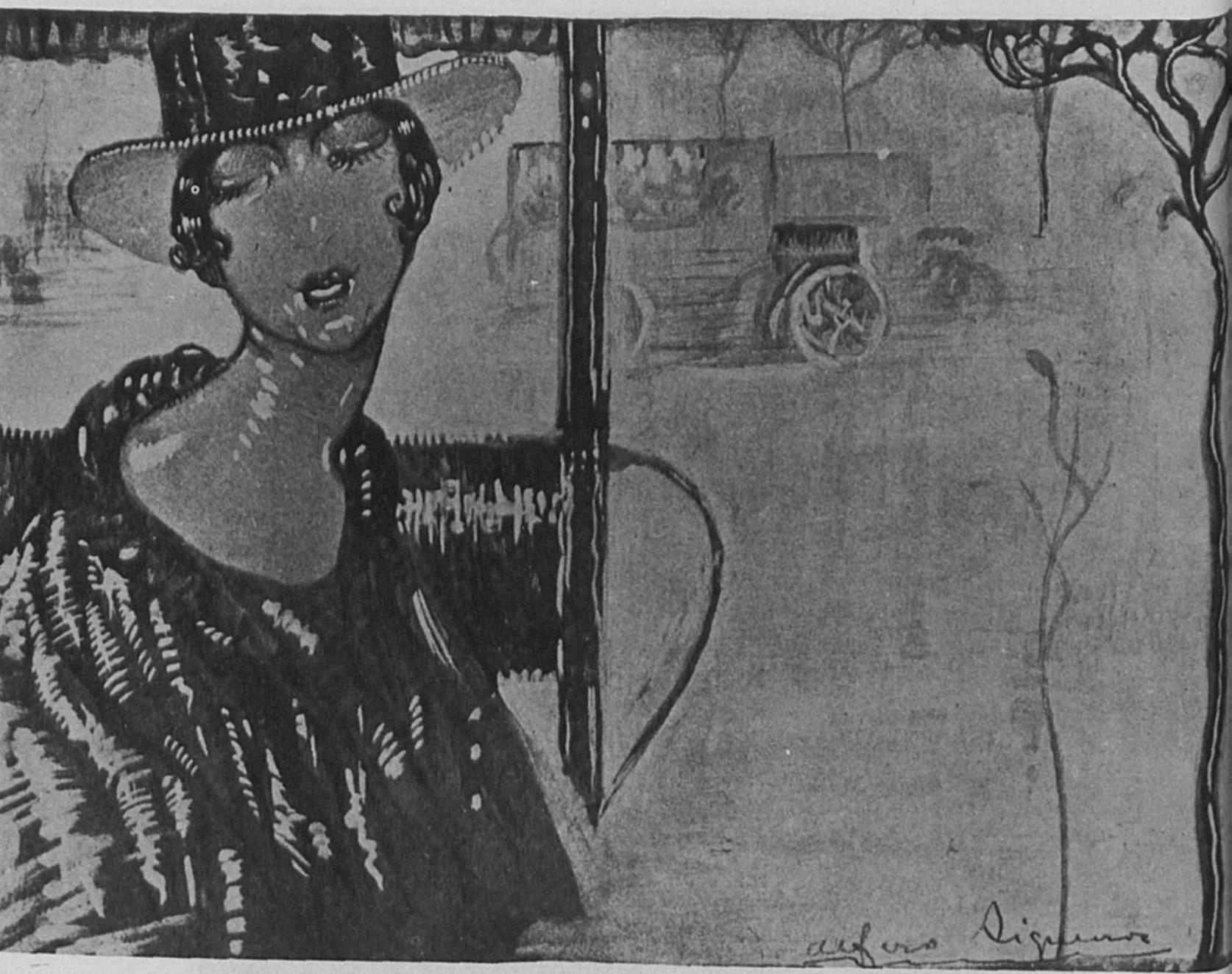

10. La señorita inconsciente. Dibujo, 1919. 


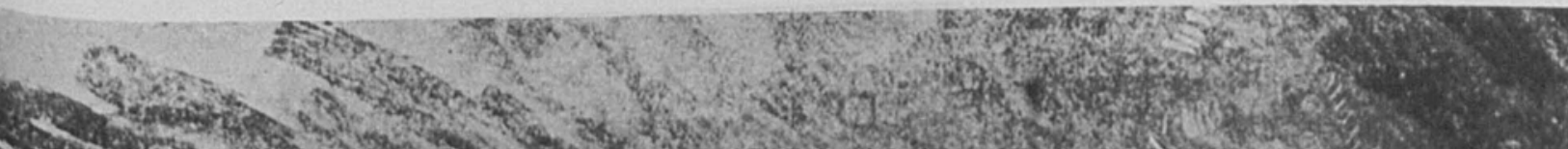
W.

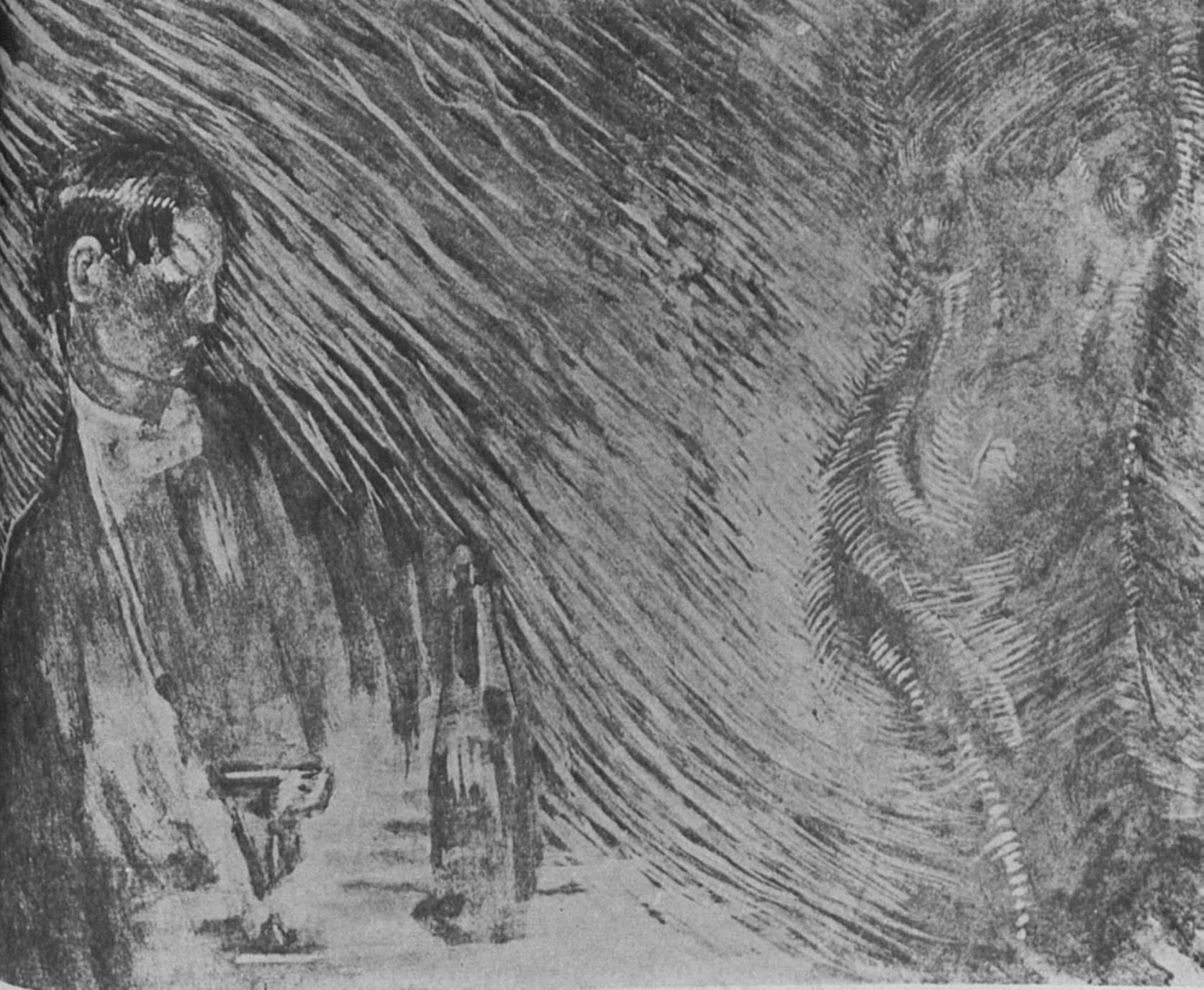

11. Bacanal. Dibujo, 1919. 


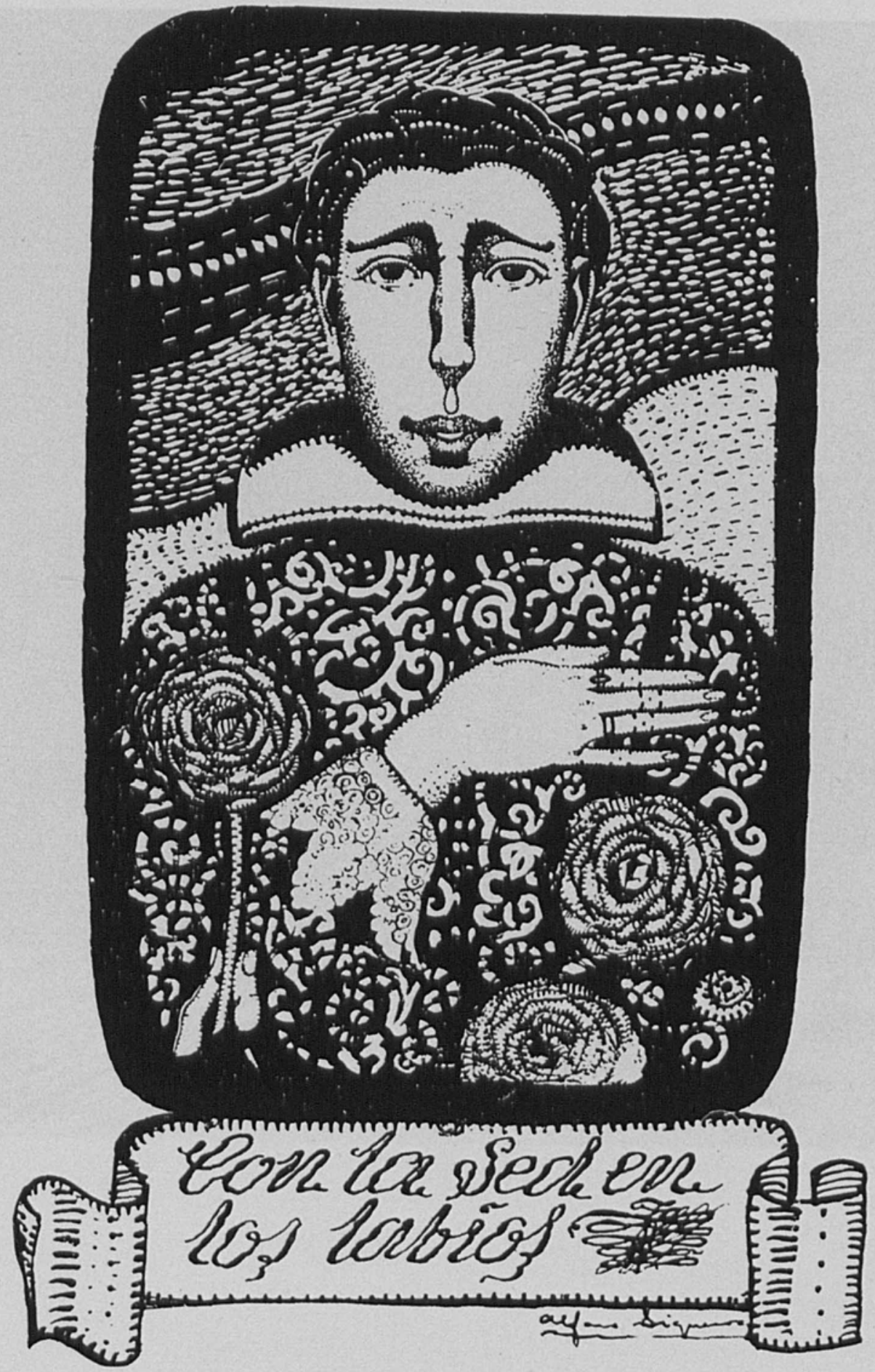

12. Con la sed en los labios (retrato de Enrique Fernández Ledezma). Dibujo. Tinta, 1919. 


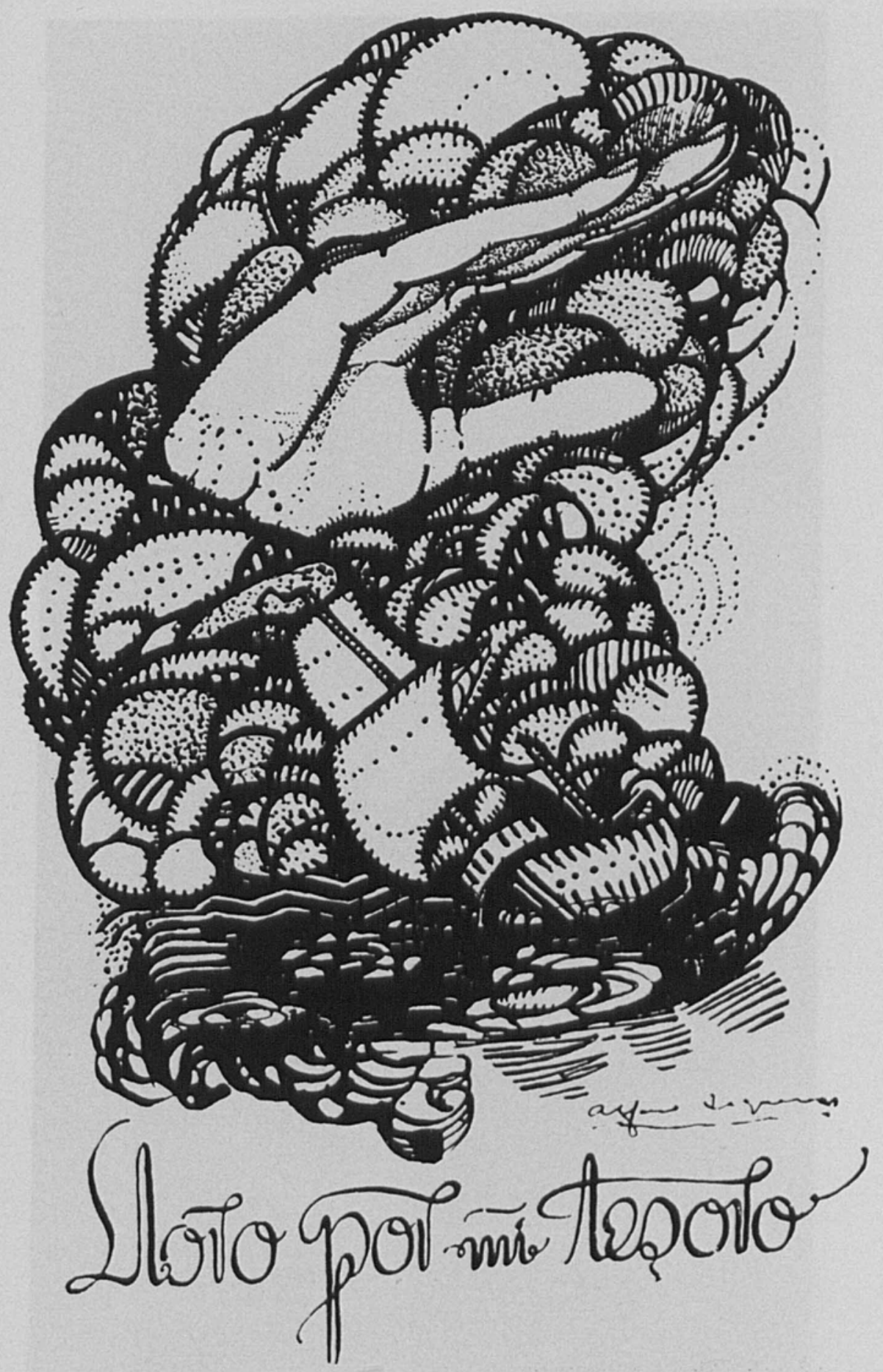

13. Lloro por mi tesoro. Dibujo. Tinta, 1919. 


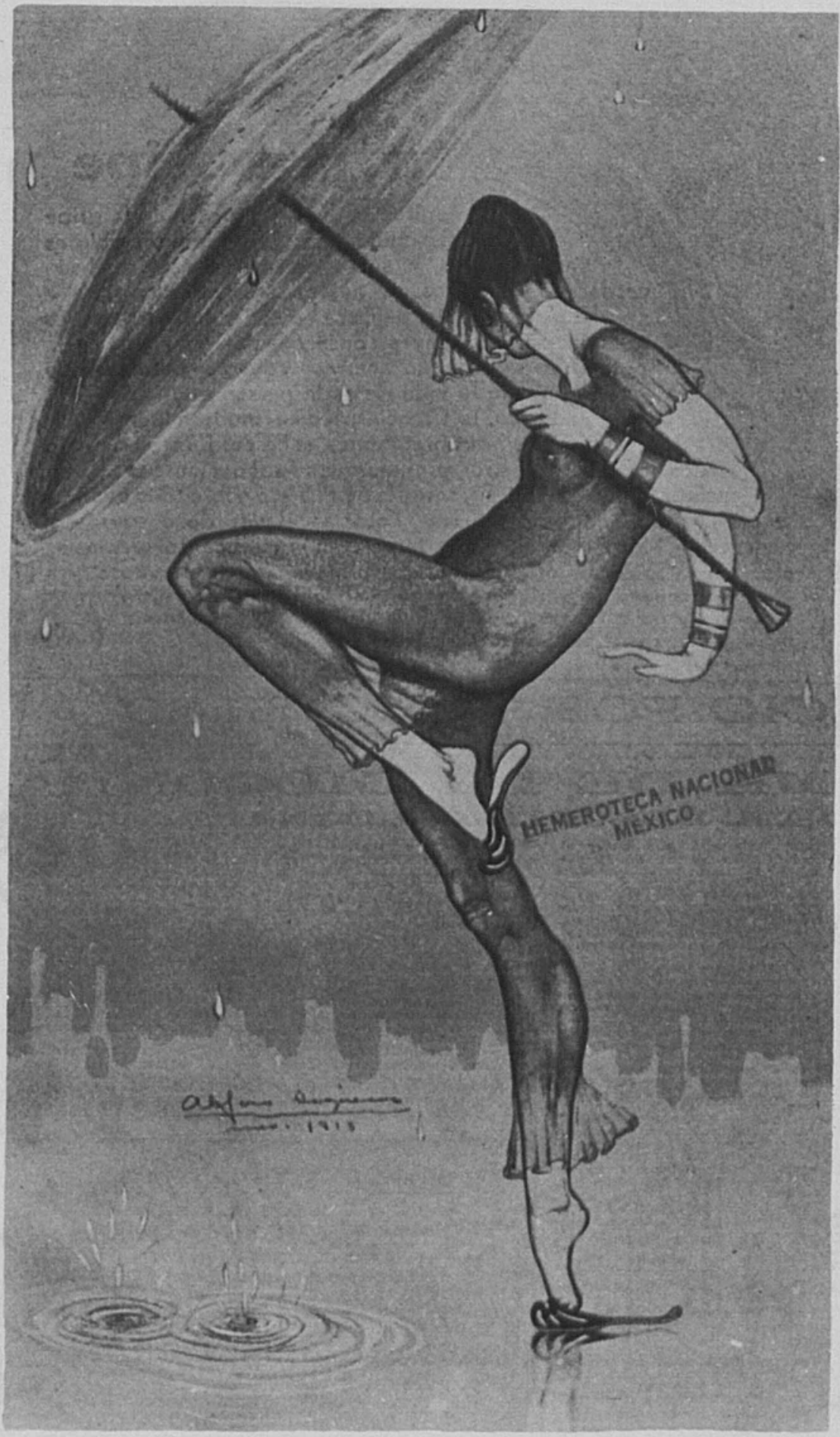

14. La danza de la lluvia. Dibujo. Tinta y acuarela, 1918. 


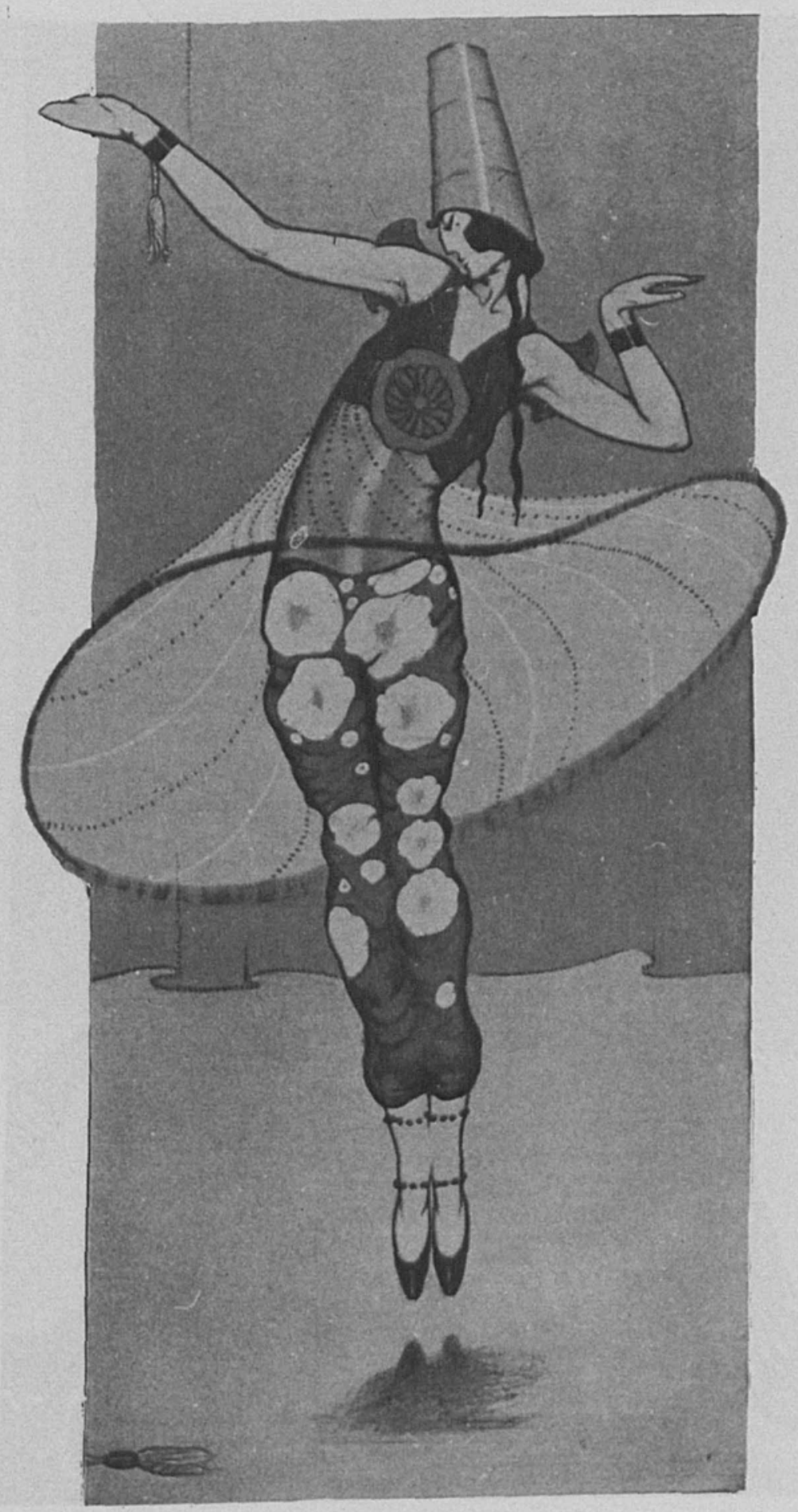

15. Bailarina oriental. Dibujo. Tinta y acuarela, 1918. 
DOI: http://dx.doi.org/10.22201/iie.18703062e.1976.45.1030

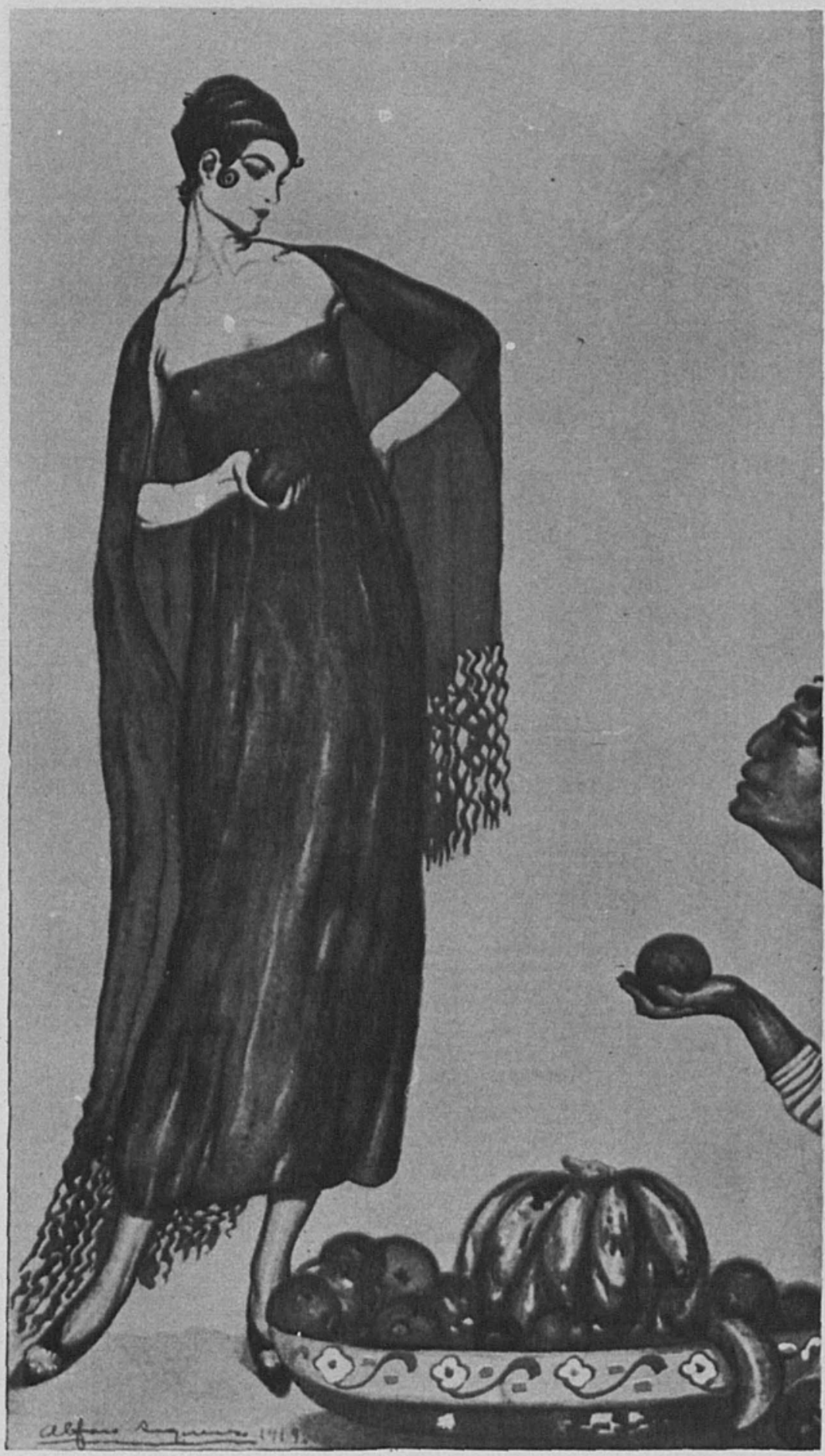

16. Los primeros frutos. Dibujo. Tinta y acuarela, 1919. 
DOI: http://dx.doi.org/10.22201/iie.18703062e.1976.45.1030

\section{8 \\ 1919}
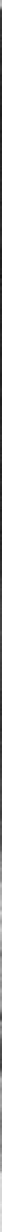

17. 1918-1919. Dibujos alegóricos, 1919. 


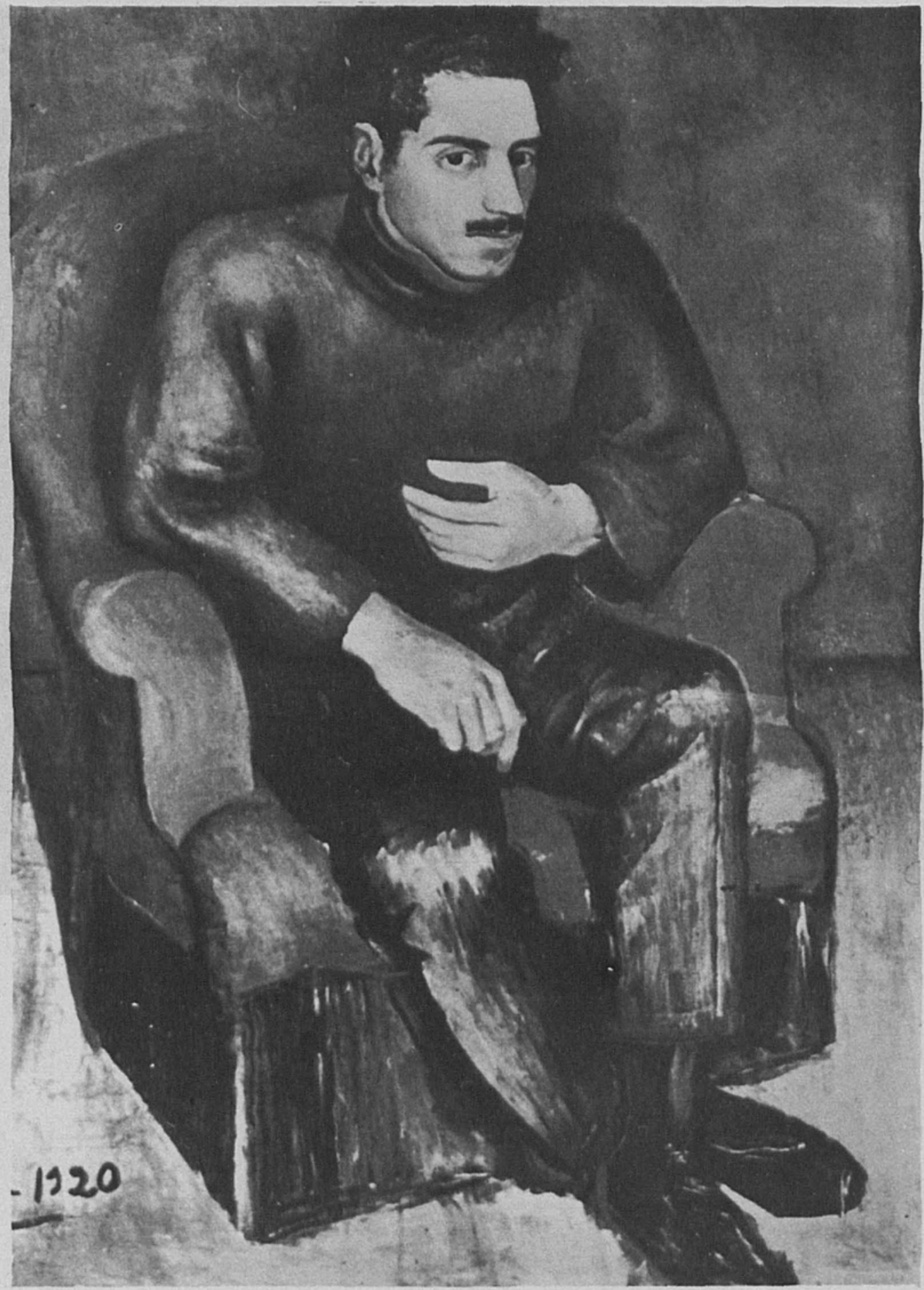

18. Amado de la Cueva. Oleo sobre tela, 1920, Guadalajara, Jal. 
DOI: http://dx.doi.org/10.22201/iie.18703062e.1976.45.1030

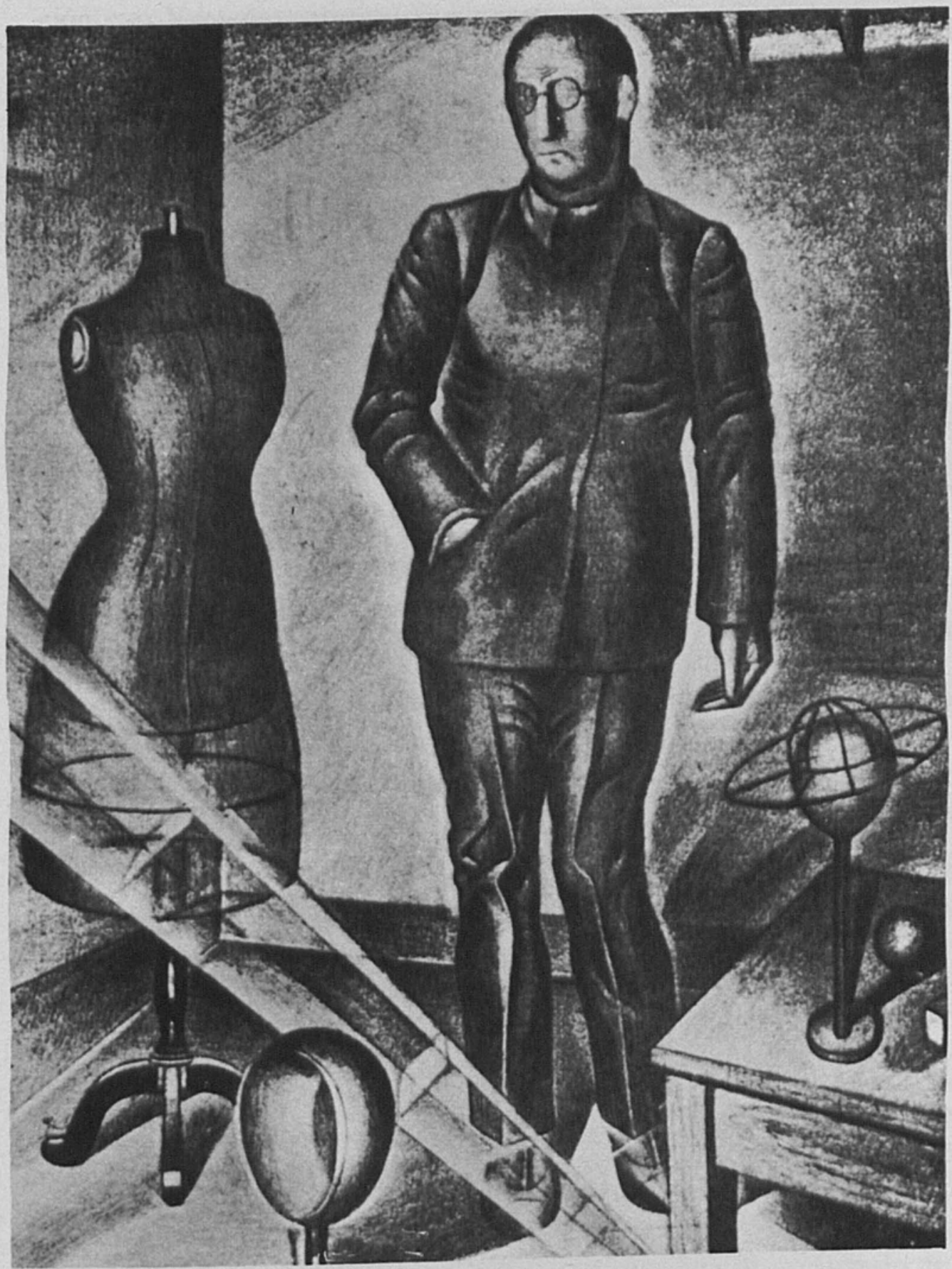

19. W. Kennedy. Dibujo, 1920. Colección Fideicomiso D.A.S. 
DOI: http://dx.doi.org/10.22201/iie.18703062e.1976.45.1030

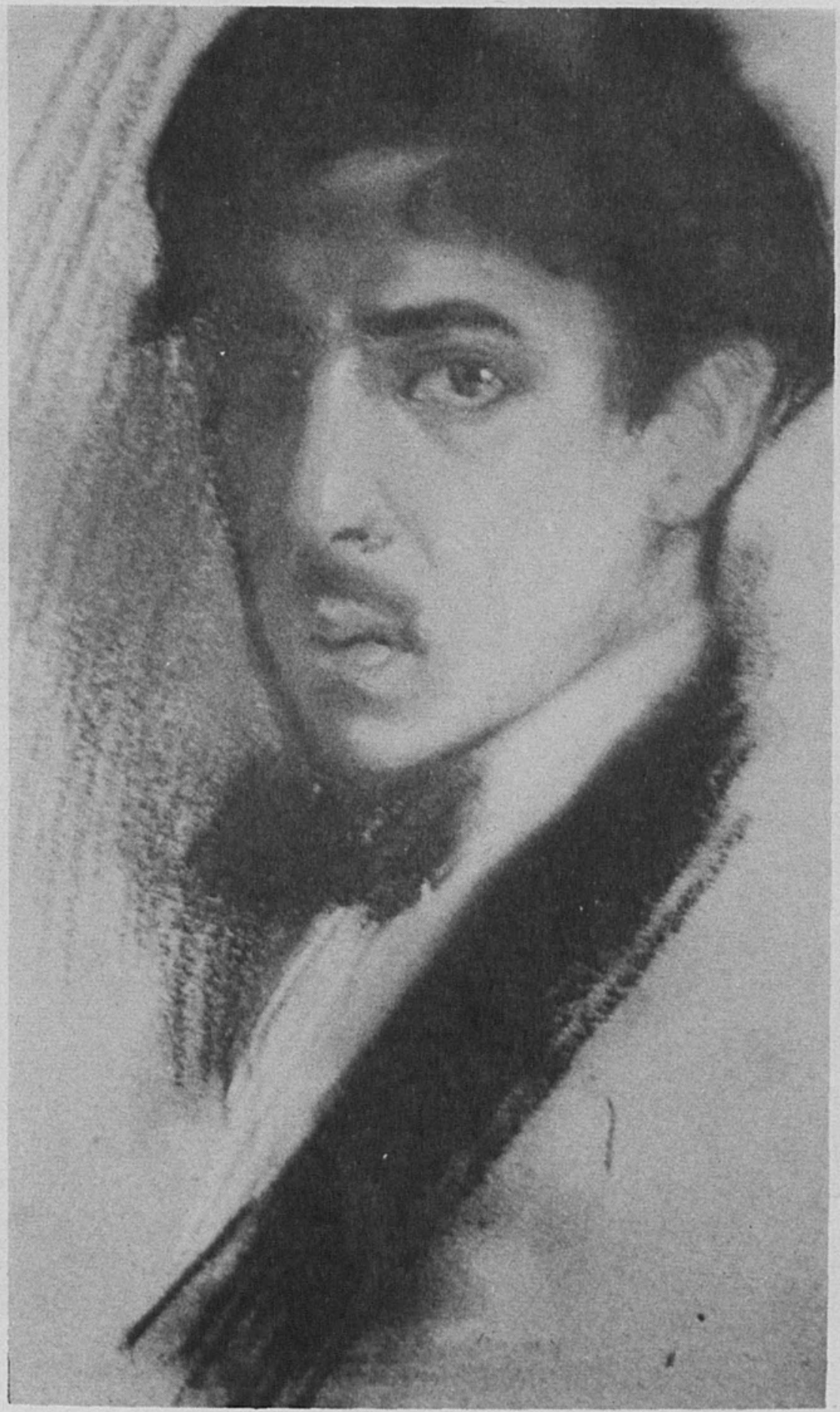

20. Autorretrato. Pastel, 1976. Museo Regional. Guadalajara, Jal. 
ción está llena de símbolos; la lentitud con la que transcurre el tiempo cronológico que comprende un año, tiempo que el hombre no puede modificar, que no le es dado alterar, por eso la marcha del año está sujeta aquí al lento movimiento del caracol. El gorro frigio sobre la testa del año nuevo es una alusión a la esperanza que por mucho tiempo albergó el hombre sobre el liberalismo desprendido de la Revolución Francesa. Los principios de Libertad, Igualdad y Fraternidad, por última vez imaginó que los había alcanzado al finalizar la Primera Guerra Mundial, de la que se llegó a decir irónicamente o con un optimismo arrancado del miedo, que era la última. Tales principios en verdad, dejaron de tener vigencia efectiva dentro de un contexto internacional, después de esa guerra. Pero aún hay más en este singular dibujo. En el fondo se muestra la portada destruida de una iglesia medieval; destruida por las bombas de esa especie de mariposa metálica que allí se ve y que no es otra cosa que el símbolo de la aviación, o sea, el presente destruyendo al pasado. La composición termina con la impresionante imagen de un Cristo en la cruz, decapitado y con las piernas destrozadas. Se puede decir que para Siqueiros, en ese momento, la guerra no sólo significó la destrucción de los bienes materiales del hombre (el edificio eclesiástico) sino que también lo fue de los espirituales.

De la estancia de David Alfaro Siqueiros en Europa conozco únicamente dos obras, se trata de dos retratos hechos en París, los incluyo aquí puesto que son obras anteriores a su retorno a México, marcan una pausa entre lo que hizo hasta 1919 y lo que habría de realizar después de 1922. El primer retrato se ocupa del pintor Amado de la Cueva, el concepto que Siqueiros tenía respecto a la composición de los retratos, ha desaparecido. Este cuadro fechado en 1920 es poco conocido, está trabajado con una gran libertad en cuanto al acabado, libertad que debió ver en las pinturas de algunos maestros europeos contemporáneos. La figura sentada ocupa todo el espacio de la tela, esa posición no deja de ser un preludio lejano de muchos retratos que pintará más tarde. Las manos tienen una importancia capital, Siqueiros como artista así debió comprenderlo y de allí la expresión que les dio; cuán lejos se encuentran de aquellas manos de largos y lánguidos dedos que vimos en los retratos anteriores. El colorido expresionista está aplicado con una violencia contrastante, en la que priva sin embargo, un rojo cálido, como la sangre que bullía en ese hombre inquieto que fue Amado de la Cueva y que habría de tener un trágico fin (figura 18).

El otro retrato es un dibujo al lápiz y corresponde a W. Kennedy, 
un sastre a quien Siqueiros conoció en París ${ }^{17}$ (figura 19). Estoy enteramente de acuerdo con Raquel Tibol en calificar a este dibujo como obra influida por la escuela metafísica, lo cual implica reconocer que Siqueiros recibió otro impacto italiano: el de De Chirico. La señora Tibol ha efectuado un esmerado estudio sobre esta obra, parte del cual me permito transcribir a continuación:

Como Giorgio de Chirico o Carlo Carrà (Siqueiros) da a la figura humana estructura de maniquí (simbólica en este caso dado que el retratado era sastre) y al maniquí condición metafísica. Modela los planos en rotundos claroscuros $\mathrm{y}$, para crear una profundidad más vibrante en el espacio, traza un prisma de luz en incisión oblicua de izquierda a derecha y de adelante hacia atrás, lo que permite mostrar un juego riguroso de luces y sombras. ${ }^{18}$

Se ha presentado en esta investigación un aspecto importante y casi desconocido de la obra de David Alfaro Siqueiros, la cual corresponde a una etapa decisiva en su formación; los límites marcados por el periodo de búsquedas y encuentros, van de 1911 a 1920. Las obras que cubren ese lapso comprenden pinturas al óleo y a la acuarela, dibujos al lápiz y a tinta; las novedades y los aciertos que hay en esa producción, el lector, con su propio juicio, sabrá valorarlos mejor. Siqueiros se ha mostrado aquí con una personalidad distinta a la del Siqueiros que comúnmente se conoce, ello justifica el título adoptado para este estudio.

La investigación no fue llevada a mayores consecuencias por diversas razones, entre ellas se encuentra el mayor obstáculo: el desconocimiento general que hay respecto al valor que poseen las obras de esta etapa. Muchas más deben encontrarse en colecciones particulares, en libros y revistas. Raziel Cabildo en su trabajo citado se refiere a los siguientes: El tuerto de las máscaras, México moderno. El vendedor de juguetes, Rusia y Las calaveras de axúcar. ¿Cuál es su paradero? Ojalá algún día se den a conocer.

Dejo constancia pública de mi agradecimiento a las siguientes perso-

17 El dibujo está fechado en 1919 y fue reproducido en la p. 11 del único número que se publico de Vida Americana.

18 Op. cit., p. 45. 
nas que me auxiliaron en la investigación: señora Raquel Tibol, maestro Francisco Díaz de León, maestro Carlos Orozco Romero, maestro Roberto Berdecio y señor Gabriel Labrador. Las fotografías se deben a: señora Inés Amor, profesora Guillermina Vázquez, profesor Mariano Monterrosa, profesor Fausto Ramírez R. y arquitecto Felipe Lacouture. 